\title{
Aquaporins: More Than Functional Monomers in a Tetrameric Arrangement
}

\author{
Marcelo Ozu 1,2, Luciano Galizia ${ }^{3,4}$, Cynthia Acuña 1,2 and Gabriela Amodeo 1,2,* \\ 1 Departamento de Biodiversidad y Biología Experimental, Facultad de Ciencias Exactas y Naturales, \\ Universidad de Buenos Aires, Buenos Aires C1428EGA, Argentina; mozu@bg.fcen.uba.ar (M.O.); \\ cin.flo.acu@gmail.com (C.A.) \\ 2 Instituto de Biodiversidad y Biología Experimental y Aplicada (IBBEA), Universidad de Buenos Aires y \\ Consejo Nacional de Investigaciones Científicas y Técnicas (CONICET), \\ Buenos Aires C1428EGA CABA, Argentina \\ 3 Instituto de investigaciones Médicas A. Lanari, Facultad de Medicina, Universidad de Buenos Aires, \\ Buenos Aires C1427ARO, Argentina; lgalizia@gmail.com \\ 4 Consejo Nacional de Investigaciones Científicas y Técnicas, Laboratorio de Canales Iónicos, \\ Instituto de Investigaciones Médicas (IDIM), Universidad de Buenos Aires, \\ Buenos Aires C1427ARO, Argentina \\ * Correspondence: amodeo@bg.fcen.uba.ar; Tel.: +54-11-528-58589
}

Received: 29 September 2018; Accepted: 7 November 2018; Published: 11 November 2018

\begin{abstract}
Aquaporins (AQPs) function as tetrameric structures in which each monomer has its own permeable pathway. The combination of structural biology, molecular dynamics simulations, and experimental approaches has contributed to improve our knowledge of how protein conformational changes can challenge its transport capacity, rapidly altering the membrane permeability. This review is focused on evidence that highlights the functional relationship between the monomers and the tetramer. In this sense, we address AQP permeation capacity as well as regulatory mechanisms that affect the monomer, the tetramer, or tetramers combined in complex structures. We therefore explore: (i) water permeation and recent evidence on ion permeation, including the permeation pathway controversy - each monomer versus the central pore of the tetramer-and (ii) regulatory mechanisms that cannot be attributed to independent monomers. In particular, we discuss channel gating and AQPs that sense membrane tension. For the latter we propose a possible mechanism that includes the monomer (slight changes of pore shape, the number of possible H-bonds between water molecules and pore-lining residues) and the tetramer (interactions among monomers and a positive cooperative effect).
\end{abstract}

Keywords: water channel; osmotic permeability; gating; cooperative mechanism

\section{Introduction}

One of the milestones in the study of water movement through biological membranes was unraveling the molecular entity, i.e., the identification of the aqueous pore or specific water channel-later named aquaporin, $\mathrm{AQP}$ - that could increase the membrane water permeability $\left(\mathrm{P}_{f}\right)$ beyond the values expected for a simple partition-diffusion process [1,2]. The requirement of aqueous pores to hold up high water permeability values - reported in specific cells or epithelia - has been largely discussed and proposed in the biophysical community for more than sixty years [3-5]. The biophysical arguments introduced by Finkelstein and others sustained that if water moves by a partition-diffusion process during osmotic events, the ratio between the osmotic $\left(\mathrm{P}_{f}\right)$ and diffusion $\left(\mathrm{P}_{d}\right)$ permeability should be $1\left(\mathrm{P}_{f} / \mathrm{P}_{d}=1\right)$, while a ratio higher than 1 should indicate that water could be moving through pores $[5,6]$. The overexpression of a red cell channel-intrinsic protein (CHIP28, now AQP1) in Xenopus oocytes, unambiguously confirmed that oocyte plasma membrane can dramatically increase $\mathrm{P}_{f}[1]$. 
The measurement of $\mathrm{P}_{f}$ immediately spread as a convenient tool among other parameters to test the impact of aquaporins in the water transfer capacity of a certain membrane. In the last two decades, structural studies have made AQPs one of the best structurally characterized membrane protein families, providing detailed information regarding the substrate specificity, mechanism of conduction and modes of regulation $[7,8]$.

In terms of permeation, AQPs belong to a widespread and complex superfamily of intrinsic membrane proteins that include AQPs that are highly permeable to water (known as orthodox aquaporins) and AQPs which might differ in their water transport capacity but facilitate the passage of small solutes (non-orthodox AQPs, including aquaglyceroporins, metalloido-porins and others) [9-12] (Figure 1A). Also, the transport of some gases is being reported in AQPs from different kingdoms [13,14], and the ion transport is being reported in certain AQPs $[15,16]$. A group of aquaporins with highly deviated Asparagine-Proline-Alanine (NPA) motifs was named as S-aquaporins (superfamily, small basic intrinsic protein (SIP)-like and subcellular-aquaporins) and should be considered in this classification [17].

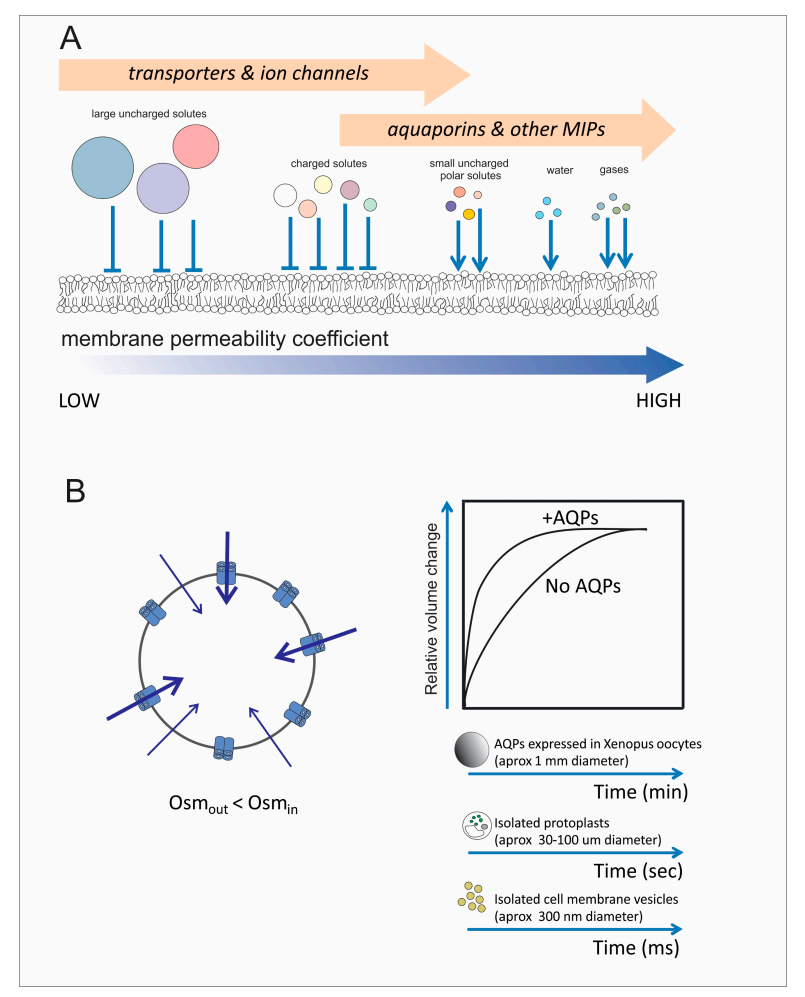

Figure 1. Biological membranes and aquaporins. (A) Biological membranes are selectively permeable. Large solutes and polar ones (e.g., ions) have very low permeability coefficients and request specific protein transporters to facilitate their transfer. On the other hand, small uncharged polar solutes as well as water and gases have less resistance to permeate through the phospholipid bilayer and protein transporters are optional. However, now we know specific channels (aquaporins) are crucial molecular entities for controlling/regulating the rate of exchange of water, gases and certain solutes including ions in certain cases. In the scheme, the arrows represent the capacity to increase the membrane permeability by introducing integral membrane proteins into the phospholipid bilayer. We propose there is an overlap in the type of transporters that can be responsible for regulating the permeation pathway of a specific solute/water/gas. (B) Water exchange is facilitated when AQPs that are water channels are present. As the phospholipid bilayer is also permeable to water, osmotic swelling is possible under an imposed osmotic gradient even in the absence of aquaporins. However, their presence allows a faster swelling response. In the cartoon it is represented the water entry and the consequent cell swelling imposed by the osmotic gradient. Different techniques are available to measure water membrane permeability in isolated cells or smaller structures. 
In terms of their quaternary structure, all AQPs are tetramers of four pores, i.e., each monomer constitutes a functionally independent pore, which is quite different from the nature of the pore of classical ion channels (Figure 2). However, the tetrameric assembly creates also a central (extra) channel of mostly hydrophobic nature with no clear role/function that it is still matter of discussion (gas/ion permeation?) [11].

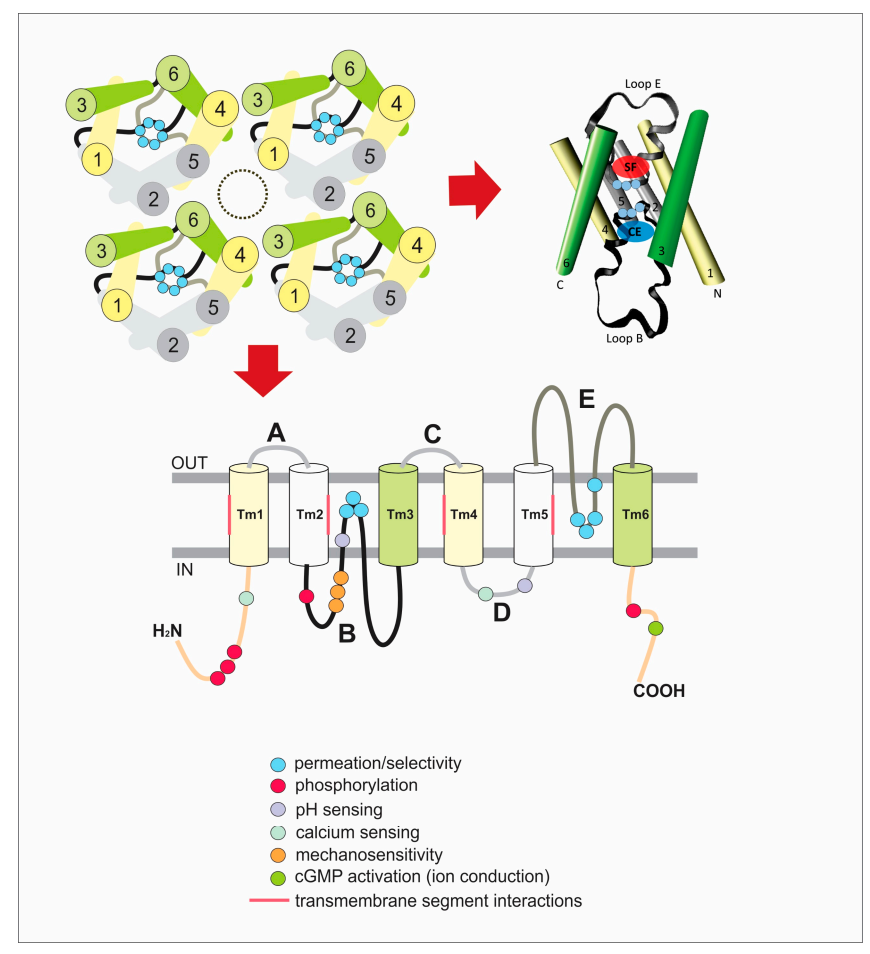

Figure 2. Scheme of the general structure of AQPs. (A) Illustration of the tetrameric organization of AQPs. Transmembrane segments (TM) are numbered from 1 to 6 . The cytoplasmic loop B (black line), the extracellular loop E (gray line) and the highly conserved NPA motifs (light blue circles) are represented. The central pore is indicated by the dash-lined oval. (B) Lateral view of one monomer. The structure representation was created with the program Visual Molecular Dynamics (VMD) (http: / /www.ks.uiuc.edu/Research/vmd/) [18] using the structural data of AQP1 (pdb 1FQY) [19]. Color code and TM numbering are the same as in $\mathrm{A}$. $\mathrm{N}$ and $\mathrm{C}$ represent both cytoplasmic $\mathrm{N}$ - and C-terminal ends. The approximated location of the selectivity filter (SF) and the cytoplasmic entrance (CE) to the single-file region are shown by transparent red and blue ovals, respectively. For detailed description see the text. (C) Schematic diagram of one monomer exhibiting its six transmembrane domains and loops. Again, the highly conserved NPA motifs and Ar/R selectivity filter are indicated in light blue circles. The topology includes information obtained from different aquaporins with the purpose of highlighting the residues or motifs that are (might be) critical for the described regulatory mechanisms. For a detailed description see the text.

In terms of conduction, an overwhelming amount of evidence (site-directed mutagenesis, structural determinations, molecular dynamics simulations, etc.) has contributed to deep inside the mechanism. Studies performed in AQP1 transformed this orthodox AQP in a channel able to transport urea, glycerol, ammonia, and even protons by manipulating the diameter of the pore by means of point mutations in the selectivity filter [20]. First high-resolution AQP structures allowed hypothesizing how water molecules move in single file through the channel with an exclusion mechanism preventing proton conduction by a Grotthuss mechanism [21,22]. Deeping inside these mechanisms continues to introduce unexpected developments in the subject [8].

In terms of regulation, one of the first and most confirmed regulatory mechanism described for mammalian AQPs was trafficking, whereby AQP membrane abundance and, consequently, 
membrane water permeability is regulated by their relocalization in intracellular storage sites [23,24]. Among a series of papers that predicted this regulatory mode to control membrane $\mathrm{P}_{f}$ years before AQPs were discovered are those that describe the nature of the water permeability adjustments induced by antidiuretic hormone in renal epithelia [25]. In this work the authors wrote: "We find that even in the unstimulated bladder, water probably crosses the luminal membrane primarily through small aqueous pores, and that this is almost certainly the case after antidiuretic hormone (ADH) stimulation. I suggest that $\mathrm{ADH}$ stimulation ultimately leads either to formation (or enlargement) of pores, by the rearrangement of preexisting subunits, or to an unplugging of these pores". Freeze fracture studies confirmed the appearance of intra-membrane particle aggregates in the ADH target membranes; the number was related to the change in water permeability [26]. These observations remarkably emphasize not only the impact of water channels to sustain the $\mathrm{P}_{f}$ but also their hormonal-controlled trafficking as a highly regulated mechanism with a physiological role. Overwhelming evidence has confirmed the role of AQP2 and other AQPs in renal physiology and pathophysiology $[27,28]$. Hormonal or environmental signals can alter $\mathrm{P}_{f}$ through this mechanism in a wide variety of eukaryotic aquaporins [29-31].

Provided the information available from structural studies, it becomes clear that certain reoccurring structural features are responsible for how aquaporin regulation might occur. At the level of the monomer, conformational changes can reversible control water flux by means of opening and closing the pore. This was nicely confirmed for $\mathrm{pH}$, phosphorylation status and calcium [32-34]. The word gating was taken from the ion channel field to describe the capacity to modulate the membrane $\mathrm{P}_{f}$. However, it must be emphasized that in most of ion channels, the control of transmembrane flux of ions is driven by large conformational changes that affect the pore-forming subunits. As in the case of trafficking, AQP gating provides a fast-response mechanism to control water fluxes in biological membranes to rapidly adjust $\mathrm{P}_{f}$.

Orthodox AQPs have proven to be one of the fastest reported transporters, probably sustained by their sophisticated but precise structural design. There is no straightforward answer to understand why four separate water channels should come together. Is it solely a request to warranty an impact in water flux capacity? Is it a way of providing a cooperative effect in quaternary structure to extend its regulatory properties? Although first evidence showed that lack of cooperativity between monomers was possible [35] different experimental approaches confirmed there are examples of cooperativity [36-39]. Certain aquaporins have proven to employ more complex arrangements: heterotetramerization, by means of combining oligomeric structures from isoforms o other AQPs. This has extensively been covered in studies performed in animal AQP4 [40], AQP0 [41] and plant Protoplast Intrinsic Proteins (PIPs) [42]. To what extent do gating and oligomeric rearrangements interact?

In this review, we explore evidence that highlights the functional relationship between the monomers and the tetramer. We attempt to integrate the current knowledge of the monomeric structural features that impact on the membrane water permeability in the context of a tetrameric structure. Within this frame, we review well-known regulatory mechanisms that rapidly adjust the unitary channel permeability ( $\mathrm{pH}$, phosphorylation, calcium, heterotetramerization), discuss the role of the tetramer on the ion transport capacity and the chain of events involved in a possible mechanism for the regulation mediated by membrane tension changes. This approach seeks to expand the current outlook of the structure-function relationship of aquaporins.

\section{AQPs and Their Impact in Swelling Kinetics}

\subsection{Membrane Water Permeability}

The initial proposal of considering AQPs as continuously open pores was challenged by evidence that certain aquaporins might remain in the membrane but modify their contribution to the osmotic water permeability $\left(\mathrm{P}_{f}\right.$ in upper case) by means of a gating mechanism. A high $\mathrm{P}_{f}$ will allow fast 
volume changes in a time scale that is dependent on cell volume, i.e., in the scale of msec for isolated membrane vesicles/liposomes (circa $10^{-5} \mathrm{~cm}$ diameter); seconds for isolated cells (circa $10^{-3} \mathrm{~cm}$ diameter) and minutes for (Xenopus) oocytes (circa $10^{-1} \mathrm{~cm}$ diameter) (Figure 1B). This analysis is considered for those AQPs that are highly involved in water transfers, i.e., usually referred as the orthodox ones.

One of the first and best studied aquaporins is AQP1 (originally named CHIP28, [1]). When AQP1 is expressed in Xenopus oocytes, membrane water permeability increases up to 20-fold above water-injected oocytes for a given osmotic gradient $\left(\mathrm{P}_{f}=0.02 \mathrm{~cm} \cdot \mathrm{s}^{-1}\right.$, compared to $\left.\mathrm{P}_{f}=0.001 \mathrm{~cm} \cdot \mathrm{s}^{-1}\right)$. However, in this system it is not always straight forward to calculate the unitary-also indicated as monomeric or channel unit-water permeability ( $\mathrm{p}_{f}$, in lower case) due to uncertainty in the level of the protein expression. Thus, the calculation of the unitary water permeability might introduce errors since two possible expressions can be used:

$$
\begin{gathered}
\mathrm{p}_{f}=\mathrm{P}_{f} \times \text { area } / \mathrm{n}_{\text {monomers }} \\
\mathrm{p}_{f}=\mathrm{P}_{f} \times \text { area } / \mathrm{n}_{\text {tetramers }}
\end{gathered}
$$

where $\mathrm{n}_{\text {monomers }}$ and $\mathrm{n}_{\text {tetramers }}$ are the number of monomers and tetramers of AQP, respectively.

Studies performed with closed lipid vesicles containing two-dimensional crystallization of AQP1 facilitated these calculations, as they provided higher accuracy in evaluating protein density [43]. As described in this study, these crystalline vesicles showed a $\mathrm{P}_{f}=0.472 \mathrm{~cm} \cdot \mathrm{s}^{-1}$ and allowed predicting a unitary osmotic permeability coefficient $\left(\mathrm{p}_{f}\right)$ of $\sim 5.4 \times 10^{-14} \mathrm{~cm}^{3} \cdot \mathrm{s}^{-1}$. The findings were also consistent with measurements performed for AQP1 in different systems showing $\mathrm{p}_{f}$ values between $6-16 \times 10^{-14} \mathrm{~cm}^{3} \cdot \mathrm{s}^{-1}[44-47]$.

How is this translated to cell-swelling kinetics? AQP1 is a $28 \mathrm{kDa}$-protein surprisingly abundant in human red cells $(\sim 1,400,000$ copies per erythrocyte) [48]. In red cells, AQP1 is therefore considered to be a main water pathway as the membrane can express other AQP types but with much lower $\mathrm{P}_{f}$ values.

Based on the calculated unit water permeability of AQP1, the AQP1-mediated osmotic permeability $\left(\mathrm{P}_{f}\right)$ of a human red cell can be estimated as:

$\mathrm{P}_{f}=\left(\mathrm{p}_{f}\right.$ of AQP1 $\times$ number of AQP1 per red cell)/(surface area of red cell) $\sim 0.017 \mathrm{~cm} \cdot \mathrm{s}^{-1}[44]$

In the literature, $\mathrm{P}_{f}$ values for intact red cells were reported to be as high as $0.02 \mathrm{~cm} \cdot \mathrm{s}^{-1}[5,49]$. If we consider the single-file model (water molecules can pass through the pore in a single-file mode) the rate turns to $1.8 \times 10^{9}$ water molecules per monomer per second. This value is much higher than those reported to move ions in channels $\left(10^{6}\right.$ ions per second) or transporters $\left(10^{-2}-10^{-4}\right.$ per second).

High $\mathrm{P}_{f}$ values can be found in more complex structures, as an epithelium where cells are polarized. As an example, in hepatic epithelial cells expressing AQP8 strong differences between apical (canalicular) and basolateral $\mathrm{P}_{f}$ have been described [50]. Canalicular membrane vesicles could achieve very high $\mathrm{P}_{f}$ values $\left(0.066 \pm 0.014 \mathrm{~cm} \cdot \mathrm{s}^{-1}\right)$ and these values can dramatically change if stimulation is avoided [50]. Trans-epithelial net volume-flux measurements in collecting duct epithelial cells expressing AQP2 suggested an osmotic flow rectification dependent on an asymmetrical modulation of $\mathrm{P}_{f}$ between apical and basolateral membranes [51].

These observations can be extended to other kingdoms. AQP1 in red cells is abundant but represents $3.5 \%$ of membrane proteins. In the plant kingdom, aquaporins constitute $5-20 \%$ of all integral membrane proteins and although reported $\mathrm{P}_{f}$ varies, selective-water channels as PIPs (mainly expressed at the level of the plasma membrane) are consistently showing high $\mathrm{P}_{f}$ [52]. In addition, the number of PIP homologs is large, and evidence shows that heterotetramerization between different PIPs can also modify intrinsic water permeability [53].

Nevertheless, the abovementioned calculations fit with the hypothesis that specialized cells, or ordinary cells submitted to specific challenges, can employ PIPs and other AQPs to regulate the rate of swelling (fast or slow) by adjusting the number of inserted proteins in the membrane and/or opening 
and closing the channel, provided that: (i) the requested density of membrane protein is feasible, (ii) reported $\mathrm{P}_{f}$ values obtained from the characterization of certain AQPs in Xenopus oocytes are consistently high, and (iii) short term regulatory properties are well described to provide a mechanism to rapidly modify $\mathrm{P}_{f}$.

\subsection{Molecular Basis of Water Permeation}

In single-file transport, the diffusion of water is governed by the capacity of water molecules to form H-bonds [54]. Molecular dynamics simulations predict that the water passage through the single-file region is limited by the time required for breaking H-bonds, reorientation of water molecules and forming new H-bonds [54]. This capacity depends on the number of pore-lining residues capable of forming H-bonds and the effective space for water molecules to form such H-bonds. Therefore, water transport through AQPs is considered not frictionless [55].

When entering the single-file region of orthodox AQPs, each water molecule loses two of the four $\mathrm{H}$-bonds formed with other water molecules. Only the H-bonds with the preceding and the following are maintained allowing water molecules in the single-file lumen to form H-bonds with the pore-lining residues [55].

Molecular dynamics simulations performed with structural data obtained at $0.88 \AA$ resolution predicted that the translocation of water molecules through the water pathway of the yeast aquaporin AQY1 occurs in a highly correlated manner at both the selectivity filter and the cytoplasmic half of the channel [22]. The selectivity filter of AQY1 has six residues capable of forming H-Bonds. However, due to steric hindrance only a fraction of the available sites is simultaneously occupied [22].

Inside the pore of rat AQP4 there are eight water molecules in the single-file region. The surface of the channel is hydrophobic, except for hydrophilic regions formed by the oxygen atoms of the main-chain carbonyl groups of H95, G94, G93 (loop B), G209, A210 and S211 (loop E) and nitrogen atoms of the side-chains amide groups N97 and N213 of the NPA motifs [56]. The electrostatic field created by the short $\alpha$-helices of loops B and $\mathrm{E}$ forces the water molecules to orient their oxygen to the amide groups of N97 and N213 allowing H-bonds with the NPA motifs. In this region the pore is $3 \AA$ of diameter, and with the exceptions of the two $\mathrm{N}$ the other residues lining the constriction are hydrophobic. Except for the central water molecule, all the rest can form H-bonds with upper and lower neighbors and one more with any of the pore-lining residues. Thus, the arrangement of the carbonyl and amide groups in the water pathway of AQP4 allows water molecules to form H-bonds with both $\mathrm{N}$ residues, which lowers the energy barrier to enter the constriction and allows for very fast water permeation [56].

Recent results show that the number of $\mathrm{H}$-bonds between water molecules and pore-lining residues determines the permeability of the monomeric (or unitary) water pathway $\left(\mathrm{p}_{f}\right)$ [54]. In addition, the charge effect at the pore entrance can account for small $\mathrm{p}_{f}$ changes, constituting a fine tuning over the hundred-fold change of $\mathrm{p}_{f}$ that the number of $\mathrm{H}$-bond forming pore-lining residues can account for [55]. While negative charges at the pore entrance or exit have no effect on $\mathrm{p}_{f}$, positive charges increase $\mathrm{p}_{f}$, possibly because positively charged residues are weakly hydrated in comparison to negatively charged residues [55].

In the cytoplasmic half of human AQP4, H95 (loop B) can move and form H-bond with C178 (loop D), constituting a possible regulatory mechanism for water permeability [57]. The displacement of $\mathrm{H} 95$ is triggered by intracellular proton concentration, determining the open state at alkaline $\mathrm{pH}$ and the close state at acidic $\mathrm{pH}$ [58]. This mechanism, predicted by molecular dynamics (MD) simulations, was thought to be similar to the well-described $\mathrm{pH}$ regulation of SoPIP2;1 $[8,59,60]$. However, this hypothesis was dismissed because the proximity of $\mathrm{H} 95$ to a conserved glutamic acid (E41) would be responsible for the stabilization of the closed state due to the trapping of the positive charge of $\mathrm{H} 95$ in the electrostatic field generated by E41 [58]. 


\section{Structural Changes That Regulate Permeation}

\subsection{Regulation of the Water Transport Capacity of the Monomer by pH, Phosphorylaton and Calcium}

Different kind of stimuli/factors such as $\mathrm{pH}$ changes, calcium concentration and phosphorylation have nicely been demonstrated to regulate $\mathrm{P}_{f}$ of certain AQPs. Although each stimulus elicits changes of different nature on a specific AQP, a common feature is the existence of reversible conformational changes of the pore structure that affects the water permeation through the monomeric pathway. Since this subject has been extensively reviewed [8,31,59-61], we just mention here the most relevant aspects. For example, $\mathrm{pH}$, calcium, and phosphorylation have been shown to regulate water osmotic permeability on a wide range of AQPs in different kingdoms.

In plant PIPs the mechanism involves a displacement of a flexible loop external to the channel pore $[33,62]$. This gating mechanism was proposed based on the high-resolution crystal structure of spinach SoPIP2;1-in closed and open conformation—and in combination with molecular dynamics studies $[33,60,63]$. In the closed state the cytosolic loop D interacts with the N-terminal, producing the insertion of a hydrophobic residue (L197) into the monomer. This closed state is thought to be stabilized in the presence of $\mathrm{Ca}^{2+}$ by interactions with key residues of the loop D (H193), loop B (S115) and the N-terminal [33,59]. When S115 is dephosphorylated, it also stabilizes the closed state; however, phosphorylation of this residue and other key serine residues at the loop D and C-terminal disrupts this stabilization and might induce an open state [33]. Also, when the $\mathrm{pH}$-sensitive residue at the loop D (H193) is protonated, the closed state is induced. This kind of mechanism involving loop movement which caps the monomer water pathway was also proposed for Pichia pastoris AQY1 in response to phosphorylation [59]. In AQY1, the closure mechanism might involve a unique conformation of the cytosolic N-terminus, which thereby closes the channel [64].

In contrast, another proposed mechanism of gating for other AQPs (e.g., AQP0, AQPZ, AQP4) implies smaller movements of few residues or a single one which pinch in upon the Ar/R constriction region and reduce the monomer size [59,60]. For example, in AQP0, $\mathrm{pH}$ and calcium regulation of $\mathrm{P}_{f}$ was reported. External histidine residues located in loop A (H40) and C (H122) of the bovine AQP0 could play a role in $\mathrm{pH}$ sensing [65]. Based on crystal structures [66,67], a pinching mechanism of $\mathrm{pH}$ gating was proposed for AQP0 [59], in which small conformational changes due to protonation pinch the Ar/R region where a unique tyrosine residue (Y23) is critical in limiting the passage of water molecules. Recent MD simulations confirms the role of this tyrosine residue in the pore occlusion by $\mathrm{pH}$ [68]. Regarding calcium regulation of AQP0, $\mathrm{Ca}^{2+}$-calmodulin interaction effect on AQP0 gating was also demonstrated. Molecular dynamics simulations and functional studies of bovine AQP0 revealed the role of $\mathrm{Ca}^{2+}-\mathrm{CaM}$ binding on $\mathrm{P}_{f}$ reduction suggesting the role of another unique tyrosine residue (Y149) located at the pore [37], producing an allosteric regulation. Recently the same group studied the molecular mechanism of this allosteric regulation of $\mathrm{P}_{f}$, as they were able to identify an unexplored region, an arginine-rich loop that connects fourth and fifth transmembrane helices, adjacent to Y149 that is proposed to be crucial in the gating of AQP0 [69].

In the case of E. coli AQPZ, MD simulations suggested spontaneous displacements of the well conserved arginine of the Ar/R selective filter R189 [70] and structural studies confirmed this proposed gating mechanism [71].

Regarding the role of Histidines, MD simulations predict that the homologous $\mathrm{H} 81$ of the plant aquaporin AtTIP2;1 moves spontaneously reaching positions that correlate with water permeation events that differ up to one order of magnitude [72]. While $\mathrm{H} 95$ is responsible for $\mathrm{pH}$ gating in human AQP4 [58], H81 is not responsible for $\mathrm{pH}$ gating in AtPIP2;1. Located in loop D, H131 was identified as the key residue in the $\mathrm{pH}$ regulation of AtPIP2;1 [73]. Besides this difference, both H95 in human AQP4 and H81 in AtTIP2;1 are in loop B, very close to the first NPA and flanked by highly conserved Glycine residues that are H-bond donors for water molecules. In the other half side of the channel, the conserved Histidine of the selectivity filter is highly mobile. 
From this evidence, two different schematic pictures describe the gating of transmembrane water channels: "capping" (plant PIPs) and "pinching" (AQP) [60]. Although phosphorylation has been deeply described as being part of trafficking mechanisms in almost all mammal AQPs [74-77], it also seems to be an intrinsic step of the gating process in certain AQPs, such as AQP4 [78] and FaPIP2;1 [79].

\subsection{AQPs That also Permeate Ions: The Central Pore versus Monomer-Permeation Controversy}

The controversial issue on ion permeation through aquaporins demands special attention because the transport of ions through channels requires a strict control to maintain cellular homeostasis. Then, if aquaporins allow ion permeation, mechanisms eliciting reversible structural modifications are needed to allow and control ion translocation. To sustain transmembrane $\mathrm{pH}$ and ion gradients that are critical in cell homeostasis, proton and cation permeation should be strictly regulated [19]. In this section, we will introduce the discussion on the mechanisms for ion permeation through AQPs.

From the beginning, it has been well known that protons are incapable of being translocated through AQP1 [44]. The mechanism of proton exclusion was predicted to be directed by an electrostatic barrier centered on the fingerprint NPA motif, and not by the interruption of the hydrogen-bonded water chain [80]. Further experimental studies using AQP1-mutants expanded this conception, enhancing the idea that the NPA and the Ar/R constriction regions are two concerted cation filters $[20,81]$. In particular, the Asparagine residues of the NPA region are postulated to repel positive charges by electrostatic interactions [82,83]. Since the electrostatic profile of AQP monomers is key in selectivity [84], then, the translocation of positive charged ions through AQP1 monomers should be restricted [83]. Can the electrostatic field that repels cations attract anions? More than a decade ago it was suggested that the NPA region functions as an anion trap, preventing anions from further conduction in GlpF [85]. However, some recent evidence confirmed the permeation of anions through monomers $[83,86]$. Here we will focus in three aquaporins that have been investigated in terms of ion permeation: AQP1, AQP6 and AtPIP2;1.

\subsubsection{AQP1 as a cGMP-Activated Cation Channel}

After some initial controversial reports [15,87], Yool's group demonstrated by means of different experimental approaches the fine-tuning mechanism of AQP1 as a nucleotide-activated ion channel that permeates cations- $\mathrm{Na}^{+}$or $\mathrm{K}^{+}-[16]$. The hypothesis for cation permation through AQP1 requires cGMP-binding and a series of conformational changes in loop $\mathrm{D}$ for allowing cation permeation through the central pore [88].

AQP1 shows ion currents that are blunted by mercurial treatment when expressed in Xenopus oocytes and exposed to intracellular cGMP analogs [89]. Site mutagenesis experiments directed to the cGMP-binding region of AQP1 confirmed the sensitivity of AQP1 to cGMP [88-90]. Moreover, mutations in loop D interfered with ion channel activation but produced little effect on water channel activity [91]. In addition, MD simulations performed to study possible conformational changes after cGMP-binding predicted movements of loop D. As far as from now, no crystallographic evidence can support these observations [91]. It was also shown that phosphorylation of a carboxy-terminal tyrosine (Y253) enhances the availability of human AQP1 to be gated as an ion channel in response to cGMP, and this mechanism has been proposed as a master switch regulating the displacement of loop $\mathrm{D}[88,92]$.

Phosphorylation was also proposed to trigger the gating mechanism for ion transport through Big Brain AQP (BIB), an AQP from Drosophila melanogaster with very low water permeability. When expressed in oocytes, BIB is a monovalent cation channel reversibly activated by tyrosine kinase signaling without any appreciable water channel activity $[93,94]$.

Which is the proposed pathway for cation permeation? As mentioned before, permeation of positive charged substances through the monomers of AQP1 is electrostatically restricted by the two concerted cation filters [81]. Differential effects of pharmacological agents on water and ion conductance were the first experimental evidence against cation conduction through the monomers of 
cGMP-activated AQP1 $[95,96]$. Since the AQP1 monomers were discarded as permeation pathways for the reported cGMP-induced cation conductance, the central pore became the new candidate for the ion permeation pathway in the subset of aquaporins with ion channel activity $[88,97,98]$. Molecular dynamics studies suggested that the occupancy of cations inside the hydrophobic central pore increases its size, enhancing ion permeability [91]. Site-directed mutagenesis studies were performed to confirm this hypothesis [88]. The central pore of human AQP1 is lined by four hydrophobic residues named VLLL (Val50, Leu54, Leu170 and Leu174) [88], located in transmembrane segments 2 and 5 (TM2 and TM5) [91]. When these hydrophobic residues are substituted by alanine, larger cations as tetraethylammonium $\left(\mathrm{TEA}^{+}\right)$can permeate AQP1 in response to cGMP [88]. In addition, differential inhibition of cation permeability was reported when a cysteine residue inside the central pore is replaced for a lysine [88]. Recent findings employing specific antagonists for blocking cation permeability but not the water permeability of cGMP-activated AQP1 have also reinforced the central pore hypothesis [92,99]. Single channel evidence in favor of the cGMP-gating of AQP1 was also reported by reconstitution into lipid bilayers. These experiments showed a large single channel conductance of approximately $150 \mathrm{pS}$ [89] with apparently smaller sub-conducting states [96].

\subsubsection{AQP6 as an Intracellular Gated Anion Channel}

AQP6-an AQP with low water permeability-was proposed to permeate anions in a $\mathrm{pH}$-sensitive manner $[100,101]$. These findings imply a $\mathrm{pH}$ gating mechanism present in this atypical AQP, although the molecular details of the involved conformational changes are still unknown. Also, $\mathrm{Hg}^{2+}$ induces the appearance of anionic currents and the increase of water permeability of RnAQP6 expressed in Xenopus laevis oocytes [100-102]. Two cysteine residues responsible for $\mathrm{Hg}^{2+}$-activation were identified, and the double mutant C155A/C190A cancelled the $\mathrm{Hg}^{2+}$-activation. It is intriguing that the binding of $\mathrm{Hg}^{2+}$ to the corresponding sites (Cys189 in human AQP1 and Cys190 in rat AQP6) leads to inhibition of AQP1 but activation of AQP6. The authors suggest that $\mathrm{Hg}^{2+}$ appears to trap rat AQP6 in a conformational state that is permeable to water and ions [102]. This pharmacological activation of AQP6 with $\mathrm{Hg}^{2+}$ leaves the pore in the maximal open state. However, it must be emphasized that as far as from now there is no physiological evidence for promoting this open state of the channel. It was suggested that if AQP6 was confined in intracellular vesicles, then local $\mathrm{pH}$ might regulate its activity [102]. Activation of AQP6 by $\mathrm{Hg}^{2+}$ produces a less selective anion current than $\mathrm{pH}$-activation-which allows cation permeation-and this might imply differences in both activation mechanisms. At the cytoplasmic mouth of the monomeric pore there is a positively charged residue (K72) that when mutated to a neutral charge generates an AQP6 with a non-selective current. These results suggest that this positive charge is crucial for AQP6 anion selectivity [100]. In the case of AQP6, cations can permeate through the monomers and $\mathrm{Hg}^{2+}$ can activate currents, therefore positive charges are not strictly repelled by NPA motifs as it was well established for AQP1 [82,83].

Although still speculative, the cation exclusion through the monomers of AQPs with conserved NPA motifs may not be a general feature. Another particular residue (T37) located opposite the Asparagines of the NPA motifs and not present in other mammalian AQPs, was reported to enhance $\mathrm{NO}_{3}{ }^{-}$permeability and to participate in anion permeation [101]. All this evidence supports the idea that AQP6-monomers have a peculiar pathway for permeation [100-102]. Other unique residue accounting for the structural peculiarities of AQP6 is Asp60, located at the crossing point between helixes 2 and 5, a site that is strictly conserved as a Glycine in the rest of mammalians AQPs. Glycines located at this position mediate the surface interaction between TM2 and TM5 from adjacent monomers in other AQPs [19]. Substitution of Asn60 by Glycine converts AQP6 in a water permeable channel eliminating ion permeation [103]. Moreover, mutation of a related residue in the same region of AQP5 (L51R) induced anion permeability in the four individual pores and cancelled the water permeability [104]. The rigidity of the protein structure could also account for the water versus ion permeation. For maintaining the efficient and continuous passage of water molecules within a narrow open pathway of 3-4 $\AA$ and $20 \AA$-length, the helixes show a certain rigidity, and alterations 
of this rigidity may allow helix displacement, expanding the pore diameter and allowing anions translocation $[83,104]$. Single channel assays performed in AQP6 showed a unitary conductance of approximately $46 \mathrm{pS}$ in standard physiological saline conditions [102].

\subsubsection{AtPIP2;1 Can Transport Ions}

Up to now, limited evidence on ion transport through plant AQPs was available $[105,106]$. However, AtPIP2;1 (orthodox aquaporin) has recently been described as the first plant aquaporin reported to permeate cations when it is expressed in Xenopus laevis oocytes and yeast $[107,108]$. Results confirmed a non-selective current with similar regulatory mechanisms to those previously reported for its activity as a water channel [34], i.e., the current is increased at both low extracellular calcium concentrations and alkaline extracellular $\mathrm{pH}$. Moreover, in AtPIP2;1 the ion current increases with a biphasic response by reduction of the external calcium concentration [107], which resembles the biphasic response reported on the water permeation of BvPIP2;1 [52]. These similarities between water permeability and ionic conductance (calcium and $\mathrm{pH}$ ) led to the interpretation that both water and ions share the same permeation pathway, i.e., the monomeric pore. Evidence in favor of this hypothesis is supported by a naturally tryptophan substitution occurring in a PIP member (VvPIP 2;5 cv. C. sauvignon) that generated a non-functional water channel when expressed in X. laevis oocytes. Based on homology modeling performed with the structure of SoPIP2;1, it was proposed that this constitutive tryptophan substitution occurs in a well conserved Glycine position (W100) located in loop B, blocking the water passage through the monomer [109]. Then, based on this naturally occurring residue substitution, site mutagenesis performed in AtPIP2;1 (G103W) cancelled both the water permeability [110] and ion conductance [107] without affecting its trafficking capacity [110]. Although more studies are necessary to understand the cation permeation pathway of AtPIP2;1, this evidence favors the role of the monomer hypothesis for ion permeation [16,107], in contrast to the relevance given to the central pore in AQP1 [111]. Although anion permeation was not observed in AtPIP2;1, the cation permeation was reported to be regulated by extracellular $\mathrm{Cl}^{-}$[107]. Interestingly, it was observed that AtPIP2;1-AtPIP1;2 heterotetramers blunt the ion transport but not the water permeability [107]. This evidence may suggest that heterotetrameric rearrangements can affect selectively permeation, as was previously shown for water permeation with tetramers from other plant species [53]. All this evidence reinforces the concept that certain AQPs have monomers that can expand their functional properties when interacting with the rest of the tetrameric components.

The existence of aquaporins that can also allow ion permeation requires modifying the present classification of this channel superfamily established into orthodox and non-orthodox AQPs. In recent years, some authors have defined these specific AQPs as "dual ion and water aquaporins" [16,111]. Interestingly, the controversial issue of ion-permeating AQPs had contributed to deep inside the required structural modifications that correlate with permeation events as well as introducing in the discussion more complex issues regarding the role of the central pore and putative permeation pathways.

During the last years, permeation of gases has been explored both in plant and animal AQPs-for a review see [11]. However, there is still no explicit evidence of conformational changes regulating the transport of gases through AQPs and there is very limited discussion about the putative permeation pathway [112]. Although some ion-permeating AQPs also evidenced gas permeation, the pathway for ions (central pore versus monomers) remains elusive.

Is there information in gas-permeable AQPs that can contribute to understand the role of conformational changes in permeation? Although experimental evidence indicates that AQP1 can permeate $\mathrm{CO}_{2}, \mathrm{NO}$ and $\mathrm{NH}_{3}$ [113-115], gas permeation through AQPs was questioned by theoretical and experimental approaches [115-117]. While experimental evidence using 4,4'-diisothiocyanato-stilbene-2,2'-disulfonic acid (DIDS) suggested that one half of $\mathrm{CO}_{2}$ permeation occurs through the central pore and the other half through the monomers [118], MD simulations predicted a preferential $\mathrm{CO}_{2}$ transport through the hydrophobic central pore of AQP1 over the 
monomers [119]. Other $\mathrm{MD}$ simulations also predicted that the preferential $\mathrm{CO}_{2}$ permeation through AQP1 over the lipid bilayer would occur depending on the membrane lipid composition [120].

$\mathrm{CO}_{2}$ and $\mathrm{NH}_{3}$ permeation events were also reported to occur through both AQP6 and the G60N-AQP6 mutant [115]. This mutant lacks anion-permeation capacity [103], suggesting that gas and ions are not sharing the permeation pathway. Recently, it was reported that AtPIP2;1 is also permeable to $\mathrm{CO}_{2}$, and that this permeation is blocked in the G103W-AtPIP2;1 mutant [107]. As water permeation is also blunted $[107,110], \mathrm{CO}_{2}$ translocation is potentially occurring through the monomers, as was proposed for cations.

\subsection{AQPs That Sense Membrane Tension Changes: The Role of the Tetrameric Structure}

From early studies, experimental results suggested that both animal and plant water channels could be regulated by osmolarity [121-126]. Indeed, it was proposed that AQPs act as osmosensors, transducing the osmolarity changes of the medium that surrounds the cells by means of a cooperative mechanism [127]. Subsequent evidence showed that intracellular volume or pressure can regulate the function of water channels, giving origin to the mechanical regulation hypothesis [128-132]. Then, the regulation of AQPs by a direct effect of membrane tension changes was tested for human AQP1 by mathematical modeling and simulation [38]. The results of this work indicate this mechanism can be reversible and support the osmosensor hypothesis [127,133] since data adjust to a positive cooperative mechanism that could involve the four subunits of the tetramer [38]. Almost simultaneously, experimental evidence supporting the regulation of VvTIP2;1 (grape) by membrane tension changes was reported [132].

Experimental demonstration for the tension-mediated regulation in animal and plant AQPs was reported by simultaneous measurements of mechanical coefficients and water transport rates in proteoliposomes with RnAQP4 (rat) [134] and Xenopus oocytes expressing BvTIP1;2 (beet) [135]. In both cases, the water permeability coefficient decreases in a nonlinear fashion with increments of membrane elasticity, as was predicted for AQP1 [38]. These results show that AQPs respond to membrane tension changes in the opposite way that mechanosensitive (MS) ion channels do. As widely reported on revisions, MS ion channels activate (open) with increasing tension [136-139]. On the contrary, MS AQPs (AQP4, AQP1, BvTIP1;2, VvTIP2;1) decrease their water transport rate when membrane tension raises, evidencing a closure event of the water pathway $[38,132,134,135]$. However, it cannot be generalized since MD simulations performed with the structure of AQY1 from the yeast Pichia pastoris predict that this AQP would open when increasing membrane curvature [64].

In analogy with the study of ion channels, the transport capacity of AQPs can be evidenced in a plot of water flux versus osmotic gradient $\left(\mathrm{J}_{\mathrm{w}}-\Delta_{\mathrm{osm}}\right)$. For mechanosensitive AQPs such as human AQP1 and BvTIP1;2, the $\mathrm{J}_{\mathrm{W}}-\Delta_{\text {osm }}$ plots show deviations from linearity with gradients higher than 100 mosmol $\cdot \mathrm{Kg}_{\mathrm{w}}{ }^{-1}[38,135]$. This deviation shows that $\mathrm{P}_{f}$ is not a constant value. In fact, since the measured $\mathrm{J}_{\mathrm{W}}$ is lower than expected, then there is a decrease of $\mathrm{P}_{f}$. This was initially supposed to be originated by two alternative hypotheses: (1) the water passage through the water pore could have a limiting step, or (2) the result could be consequence of a gating mechanism mediated by membrane tension [126]. Updated evidence suggests that these two hypotheses could be part of the same mechanism. In the next paragraphs we review the facts that support this proposal.

As was exposed in Section 2.2, molecular basis of water permeation indicates that $\mathrm{P}_{f}$ values are dependent on the number of $\mathrm{H}$-bonds that water molecules form with pore-lining residues [54]. In addition, results obtained with rat AQP4 reconstituted into proteoliposomes formed by phospholipids of different length showed that $\mathrm{p}_{f}$ decreases with increasing the bilayer thickness, evidencing a hydrophobic mismatch effect [140]. Moreover, this $\mathrm{p}_{f}$ decrease concurs with a geometrical change of the pore entrance at the cytoplasmic side. The pore radius increases changing the angle of the conical shape of the cytoplasmic entrance [140], where H-bond forming Glycine residues are located [56]. Similar results were predicted by simulations performed by combining analytical modeling with finite-element calculations in artificial nanopores. These simulations show that the 
conical entrance of the pore optimizes its unitary water permeability and that the best angles are similar to those observed in AQPs [141]. This evidence suggests that increasing the diameter of the pore entrance can affect the optimal distance for H-bonds between water molecules and the pore-lining residues.

Revisions on MS ion channels hypothesized that mechanical regulation would be a very ancient trait $[137,138]$. According to the pool of evidence, a MS ion channel must have a helix (a sensor) directly coupled to a pore-lining helix to be gated by the lateral tension of the membrane [139]. Usually, this coupling is mediated by Glycine residues. Thus, it was proposed that the GxxxG motif, which is characteristic of transmembrane segments [142], is also responsible for mediating mechanotransduction [143]. These features characterize the gating mechanism of MS ion channels, considering that the pore is formed by transmembrane segments from different subunits that change their position in the membrane [136]. Unlike to MS ion channels, each monomeric subunit conforms a water pathway in AQPs, and the transmembrane segments lining the pore constitute a rigid structure. This feature is one of the reasons why so many structures of AQPs were resolved with very high resolution ( 2 $\mathrm{A}$ ) [11]. Moreover, the key structural feature of AQPs are the long loops B and E that immerse deep inside the lipid bilayer, setting two short $\alpha$-helixes, $\mathrm{H}$-bond forming residues, the two NPA motifs and the selectivity filter in the core of the membrane [11].

Besides the differences between AQPs and ion channels, the GxxxG sequence appears several times in the primary structure of AQPs (6 times in human AQP1). Intriguingly, this sequence is present not only in TM segments but also in loop B, just before the first NPA, a key region for water transport [135]. In addition, the Glycine and Histidine residues that form $\mathrm{H}$-bonds with water molecules at the cytoplasmic entrance before the single-file region constitute the GxxxG sequence in AQPs $[54,56]$.

This evidence gives a picture of the stepwise movement of water inside the pore. However, beyond the monomeric scale, other reports show interactions between monomers and that water transport rates can be modified by heterotetrameric conformation. The tetrameric structure of AQPs is stabilized by interacting forces between TM1 and TM2 from one monomer with TM4 and TM5 from the adjacent monomer $[19,144]$. These interactions are mediated by Glycine residues. In addition, the intracellular loop D contributes to tetramer stabilization [145].

At the other side of the membrane, the structural differences of extracellular loops from different types of AQPs are related to differential interactions with the lipid bilayer. In the orthodox aquaporin Z (AQPZ) from E. coli [146], the extracellular loop C is shorter than in the aquaglyceroporin GLpF [147], which possesses a more pronounced secondary structure. Thus, the height of the protrusions registered by atomic force microscopy (AFM) is shorter in AQPZ than in GLpF. High-speed atomic force microscopy (HS-AFM) records demonstrated that while lateral stiffness of loop C from GLpF is slightly dependent on the plane of the membrane (X-Y axis), the lateral stiffness of loop C from AQPZ is asymmetric, being less stiff in the direction connecting helixes 3 and 4 (TM3 and TM4) than in the perpendicular direction [147].

Evidence from different plant species (maize, rice, strawberry, red beet) show that PIP1 and PIP2 isoforms can form heterotetramers with different stoichiometry [39,53,148-151]. Both loops A and D seem to be important for tetramer stabilization and modulation of the water transport rate [148,149]. In strawberry and red beet, PIP1-PIP2 heterotetramers show different water permeability values according to the stoichiometric combination of each type of monomer [39,53,79], demonstrating that the different water transport capacity exhibited by PIP1-PIP2 heterotetramers is consequence of the environmental features faced by a monomer, which are determined by its neighbors. In accordance to this, recent MD simulations predict that TM-segment interactions in PIP1-PIP2 heterotetramers from maize modulates the water permeability of PIP1 monomers [152].

Since there is a hydrophobic coupling between protein function and bilayer material properties, Lundbaek and coworkers stated that "the bilayer becomes an allosteric regulator of membrane protein function" [153], as was previously cited [134]. Molecular dynamics simulations predicted that the 
interaction of sheep AQP0 (PDB 2B6O) with the first shell of lipids are mediated by H-bonds that are not restricted to one phospholipid molecule but rather to all the lipids (7-9 lipids) forming the annular shell around the tetramer [154]. Instead of being a fixed shell, as occur with some ion channels, the annular lipids around AQPs are predicted to be interchanged with the bulk lipids of the membrane, and that this pattern would be conserved in all AQPs [155].

Based on the evidence reviewed in this section, a possible mechanism for membrane tension regulation can be proposed (Figure 3). Membrane tension increments can be translated to the tetramer by direct interaction between the protein and the lipids $[147,154,155]$. Then, the increase of membrane tension could modify the balance of the hydrophobic mismatch between the protein and the lipids [140], which could produce slight distortions of the monomers. Next, this could increase (or at least modify) the distance needed for water molecules to form $\mathrm{H}$-bonds with pore-lining residues, as e.g., at the cytoplasmic entrance before the single-file region [140], where key Glycine and Histidine residues are located [56,58]. This would result in a decrease of the probability for water molecules to form H-bonds with the protein. Since the water permeability values correlates with the number of these H-bonds [54], then the monomeric water permeability would decrease. In addition, this could be affected by the interactions among monomers $[19,144,145]$, which could produce a positive cooperative effect on $\mathrm{P}_{f}$ decrease [38].

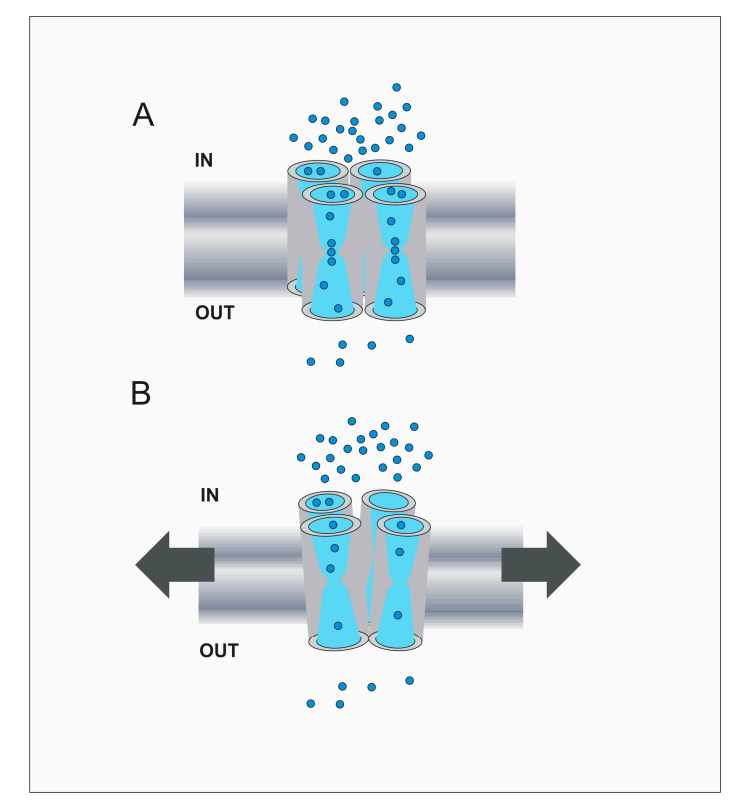

Figure 3. Schematic representation of AQP regulation mediated by membrane tension increments. (A) Illustration of a tetramer in a membrane subjected to basal tension. The applied osmotic gradient is represented by the different amount of water molecules (light blue circles) between extracellular and intracellular compartments (OUT and IN, respectively). The water pathway is schematically represented in each monomer. Since the membrane is not subjected to extra tension at the beginning of the osmotic response, the four monomers are not subjected to extra strain and the water permeability is high. (B) The development of the osmotic response produces increments of cell volume and pressure, and hence the increase of membrane tension [38,135], represented by arrows. This could produce slight distortions on the tetramer as well as slight distortions on each monomer. In mechanosensitive aquaporins we propose that these changes affect the distance between water molecules and the pore-lining residues that participate in H-bonds, e.g., at the cytoplasmic entrance to the single-file region [140]. Consequently, the probability for a water molecule to form H-bonds with pore-lining residues would be lower, producing a decrease of the unitary water permeability [54]. These events that occur in each monomer could be affected by the interactions with its neighbors, what could produce a cooperative effect for $\mathrm{P}_{f}$ decrease [38]. This scheme is inspired on the cooperative mechanism proposed by Hill et al. and used to formulate the osmosensor hypothesis [127,133]. 


\subsection{Beyond the Tetrameric Structure}

Although the tetrameric structure of almost all AQPs determines their function as water channels, some AQPs conform supramolecular assemblies allowing membrane-membrane interactions. Some examples of interactions between cells (junctions) and within the same cell (arrays) where observed [156]. Thus, the term "adhennel" has been coined for membrane proteins that function both as a cell-adhesion molecule and a membrane water channel [157]. The structures of supramolecular assemblies and the mechanisms that regulate assembly formation have been extensively investigated in AQP0 and AQP4 [66,67,157], observing some similarities between them [41]. Both AQP0 and AQP4 conform orthogonal arrays in vivo (native membranes) $[158,159]$ and were found in membrane junctions that are probably constituted by these arrays $[157,160]$. Also, the existence of long and short forms has been reported in both proteins. In AQP0 these forms are produced because of proteolytic cleavage [161], and in AQP4 because of the expression of two splicing variants (M1 and M23) [162]. The shorter protein species are most likely to conform orthogonal arrays, particularly in the case of AQP4 [163,164]. Regarding functional aspects of these isoforms, expression of the truncated form of AQP0 in Xenopus laevis oocytes suggests that cleavage does not affect the passage of water [165]. Also, both isoforms of AQP4 were observed to have the same water permeability [115]. However, structural evidence indicates that junction formation closes the water channel of AQP0 $[66,67]$ and obstructs the extracellular channel entrance in AQP4 [157].

\subsubsection{AQP0}

It is well known that the proteolitic cleavage in the cytoplasmatic side is a necessary step to the junction formation. After cleavage, structural changes occur, followed by the alignment of AQP0-tetramers from two adjacent cells. Thus, tetramers face each other from the extracellular side and the junction is stabilized by interactions between residues of extracellular loops $\mathrm{A}$ and C [66]. At the center of the tetramer a rosette-like structure is formed, mainly mediated by P38 [67]. Also, R33 is critical in the junction formation. Substitution of this Arginine by a Cysteine diminishes cell-adhesion properties in vitro [166] and causes congenital cataracts in humans [167]. On the other side, experiments in Xenopus laevis oocytes demonstrated that proteolytic cleavage does not affect the water permeability of AQP0 [165]. Structural studies suggest that junctional AQP0 is in a closed state [66] and molecular dynamics simulations indicate the junction does not affect $\mathrm{P}_{f}$ [168]; however, functional evidence on transport properties of junctional AQP0 is still lacking. An unusually narrow water permeation pathway is observed in AQP0 [168,169]. The monomeric pore contains only seven water molecules [67,168] instead of the eight or nine present in other AQPs [170]. A particular Tyrosine residue near the Ar/R site (Y23 or Y24) $[156,171,172]$ interrupts the H-bonds continuity at the center of the water channel $[168,171]$. An additional constriction region formed by residue Y149 in AQP0 [171] interrupts the H-bonds continuity, which seems to be necessary to allow water conductivity $[54,69]$ and affects the electrostatic profile of the pore [84]. However, a closed state of $\mathrm{AQP0}$ is thought to be achieved after the junction is formed. In this closed state, the number of water molecules in each monomer was shown to be reduced to only three, with distances too far apart to form H-bonding contacts $[67,156]$. Two residues were proposed to be crucial in this H-bonding interruption, a Methionine (M176) at the Ar/R selective filter and a Tyrosine (Y124) at the cytoplasmatic side of the pore [67]. Therefore, the access of water to the single-file region is restricted from both the cytoplasmic and extracellular sides of the channel. Molecular dynamics simulations indicate that both the low water permeability in the junctional and non-junctional AQP0 is a consequence of the combination of both a static barrier and dynamic gating motions [168]. These conformational changes in the closed state of the junctional AQP0 are not observed in the cleavage protein, suggesting the idea that interaction during the junction formation and not the cleavage per se produces this closure $[67,172]$. A reorientation of the Y149 [60] was proposed to occur after the protonation of H66 [66]. Recently this histidine was reported to be crucial in $\mathrm{pH}$ sensitivity of AQP0 [68]. 


\subsubsection{AQP4}

AQP4 is usually observed in two isoforms (M1 and M23). Although M1-AQP4 exists mainly as individual tetramers [173], the formation of square arrays is observed only in presence of the shorter isoform, M23-AQP4 [164]. The formation of these arrays is supposed to not affect per se the water osmotic permeability of AQP4 because similar $\mathrm{P}_{f}$ values are observed when the two isoforms are expressed in Xenopus laevis oocytes. However, the possibility of differences in the permeation capacity has been discussed as the $\mathrm{M} 23$ isoform can permeate $\mathrm{CO}_{2}$ but $\mathrm{M} 1$ has impaired gas conduction [115]. Interaction of tetramers in a junction arrangement requires an organized array [156]. As reported in AQP0, interactions of unique Prolines in the extracellular domain of AQP4 were proposed to stabilize the junction formation [56,157]. These Prolines were not observed in other mammalian AQPs [156]. However, in AQP4 one tetramer is proposed to interact with four other tetramers in the adjoining membrane, partially blocking the water-conducting channel $[41,156]$. Then, on one hand, AQP4-junctions must be formed only in the case of orthogonal arrays, and on the other hand, a water permeation junction must constitute a resistance for water permeability across the two membranes because of the partial blockage of the water pores.

Although AQP4 may form junctions, there are controversial results regarding the cell adhesive properties in vivo. In glial cells, junctional membrane zones were observed and AQP4 was detected by gold labeling [174]. Also, increased cell-adhesion properties of AQP4-expressing cells were detected [157]. However, when different cell lines were evaluated, AQP4 did not promote cell adhesion. Moreover, binding of the AQP4 extracellular domain to a peptide, proposed to promote tetramer interaction, also failed [175]. Different permeation molecules and cell-adhesion properties of junction formation water channels—such as AQP0 and AQP4—remains elusive. Therefore, further explorations of these properties are needed. Indeed, new candidates may be identified, as for example SoPIP2;1, which has also been proposed to form double-layered arrangements [41,176].

\section{Conclusions and Perspectives}

Recent research in the field of AQPs has increased our knowledge of their regulation mechanisms. Nowadays, we have information that embraces functional changes with molecular details. New evidence reinforces the concept that certain AQPs can expand their membrane properties when their functional monomers interact with each other.

The impact of aquaporins on water membrane permeability adjustments as a response to physiological processes must be taken into consideration when analyzing physiology and pathophysiology [27-31]. Solute-permeable aquaporins are also unexpectedly emerging as critical selective transporters with physiological implications [9-12]. However, ion-permeable aquaporins not only represent a challenge in the understanding of their physiological role in biological membranes as ion transporters but also because they promote the study of the molecular basis of ion permeation in these proteins as a whole. This is of particular interest in AQPs that are well known for being highly permeable water channels [89-92,107]. Also, this subject can introduce some new light in the role of the central pore. Furthermore, exploring the impact of conformational changes in permeation with new approaches could be relevant for the study of specific ion-permeable aquaporins. Also, new unexplored questions could be raised.

When considering the functional monomer and its capacity to transport water, evidence shows that water permeability in AQPs is governed at the molecular level by the ability of water molecules to form H-bonds with pore-lining residues and, (if applies) by the restriction of the water pathway by certain mechanisms (e.g., pinching or capping). However, in certain AQPs, this capacity is affected by the interactions between monomers, as demonstrated by heterooligomerization or response to membrane tension. Evidence also confirms that in certain AQPs the tetrameric conformation is modulated by interactions with the lipid bilayer or even with other tetramers-or other proteins-in supramolecular arrangements. Thus, from the monomer to the tetramer, different levels of regulation can operate and in consequence increase the output response. 
Two recent revisions explore simultaneously animal and plant aquaporins with the aim to integrate the knowledge of aquaporins inside a unique mainframe [11,177]. One unresolved issue in this approach of integration is to pursue (if plausible) for a consensual nomenclature that could improve our approach to seek information that is relevant. In previous work we proposed, among others, to find a classification based on the evolutionary framework that could also help to improve our capacity to predict permeation/selectivity and structure-function features $[178,179]$. Between the described animal membrane intrinsic proteins (MIPs) and the plant subfamilies there is possibility to restrict to four ancestral subfamilies: (A) AQP1-like and PIP, (B) AQP8-like and tonoplast intrinsic proteins (TIP), (C) AQP3-like and nodulin26-like intrinsic proteins (NIP), and (D) AQP11-like and the SIP subfamilies [178]. If we consider the abovementioned framework, we can show that almost all ion-permeable AQPs described in this review belong to subfamily (A). Also, growing evidence of lactic acid transport can be found in AQPs belonging to subfamily (C) [83], which includes the anion channel soybean NOD26 [105]. No evidence of ion transport in the subfamily (B) or (D) is available. On the other hand, mechanosensitive aquaporins are as far as from now restricted to subfamily (A) and (B). The aquaporins are ancestral channels as are some of their traits and this must be taken into consideration. Thus, this framework or an improved version might contribute to better search for connections.

Finally, we found the breakthrough in the field since the AQPs were discovered encouraging, as well as how much remains to be explored.

Funding: This review research was funded by FONCYT grants number Préstamo BID PICT14 0744 and PICT17 2338 (to G.A.), PICT17 0368 (to M.O.) and PICT14 0357 (to L.G.), and by the Universidad de Buenos Aires grant number UBACyT18-20 (to G.A. and M.O.).

Conflicts of Interest: The authors declare no conflict of interest.

\section{References}

1. Preston, G.M.; Carroll, T.P.; Guggino, W.B.; Agre, P. Appearance of water channels in Xenopus oocytes expressing red cell CHIP28 protein. Science 1992, 256, 385-387. [CrossRef] [PubMed]

2. Mathai, J.C.; Agre, P. Hourglass pore-forming domains restrict aquaporin-1 tetramer assembly. Biochemistry 1999, 38, 923-928. [CrossRef] [PubMed]

3. Paganelli, C.V.; Solomon, A.K. The rate of exchange of tritiated water across the human red cell membrane. J. Gen. Physiol. 1957, 41, 259-277. [CrossRef] [PubMed]

4. Parisi, M.; Bourguet, J. The single file hypothesis and the water channels induced by antidiuretic hormone. J. Membr. Biol. 1983, 71, 189-193. [CrossRef] [PubMed]

5. Finkelstein, A. Water Movement Through Lipid Bilayers, Pores, and Plasma Membranes: Theory and Reality; John Wiley \& Sons Ltd.: New York, NY, USA, 1987.

6. Parisi, M.; Amodeo, G.; Capurro, C.; Dorr, R.; Ford, P.; Toriano, R. Biophysical properties of epithelial water channels. Biophys. Chem. 1997, 68, 255-263. [CrossRef]

7. Sachdeva, R.; Singh, B. Insights into structural mechanisms of gating induced regulation of aquaporins. Prog. Biophys. Mol. Biol. 2014, 114, 69-79. [CrossRef] [PubMed]

8. Kreida, S.; Tornroth-Horsefield, S. Structural insights into aquaporin selectivity and regulation. Curr. Opin. Struct. Biol. 2015, 33, 126-134. [CrossRef] [PubMed]

9. Verkman, A.S. Aquaporins at a glance. J. Cell. Sci. 2011, 124, 2107-2112. [CrossRef] [PubMed]

10. Pommerrenig, B.; Diehn, T.A.; Bienert, G.P. Metalloido-porins: Essentiality of Nodulin 26-like intrinsic proteins in metalloid transport. Plant. Sci. 2015, 238, 212-227. [CrossRef] [PubMed]

11. Sutka, M.; Amodeo, G.; Ozu, M. Plant and animal aquaporins crosstalk: what can be revealed from distinct perspectives. Biophys. Rev. 2017, 9, 545-562. [CrossRef] [PubMed]

12. Ishibashi, K.; Morishita, Y.; Tanaka, Y. The Evolutionary aspects of aquaporin family. Adv. Exp. Med. Biol. 2017, 969, 35-50. [CrossRef] [PubMed]

13. Bienert, G.P.; Chaumont, F. Aquaporin-facilitated transmembrane diffusion of hydrogen peroxide. Biochim. Biophys. Acta 2014, 1840, 1596-1604. [CrossRef] [PubMed] 
14. Kaldenhoff, R.; Kai, L.; Uehlein, N. Aquaporins and membrane diffusion of $\mathrm{CO}_{2}$ in living organisms. Biochim. Biophys. Acta 2014, 1840, 1592-1595. [CrossRef] [PubMed]

15. Yool, A.J.; Stamer, W.D.; Regan, J.W. Forskolin stimulation of water and cation permeability in aquaporin 1 water channels. Science 1996, 273, 1216-1218. [CrossRef] [PubMed]

16. Kourghi, M.; Pei, J.V.; De Ieso, M.L.; Nourmohammadi, S.; Chow, P.H.; Yool, A.J. Fundamental structural and functional properties of aquaporin ion channels found across the kingdoms of life. Clin Exp. Pharmacol. Physiol. 2018, 45, 401-409. [CrossRef] [PubMed]

17. Ishibashi, K. Aquaporin superfamily with unusual npa boxes: S-aquaporins (superfamily, sip-like and subcellular-aquaporins). Cell. Mol. Biol. 2006, 52, 20-27. [PubMed]

18. Humphrey, W.; Dalke, A.; Schulten, K. VMD: Visual molecular dynamics. J. Mol. Graph. 1996, 14, $33-38$. [CrossRef]

19. Murata, K.; Mitsuoka, K.; Hirai, T.; Walz, T.; Agre, P.; Heymann, J.B.; Engel, A.; Fujiyoshi, Y. Structural determinants of water permeation through aquaporin-1. Nature 2000, 407, 599-605. [CrossRef] [PubMed]

20. Beitz, E.; Wu, B.; Holm, L.M.; Schultz, J.E.; Zeuthen, T. Point mutations in the aromatic/arginine region in aquaporin 1 allow passage of urea glycerol, ammonia, and protons. Proc. Natl. Acad. Sci. USA 2006, 103, 269-274. [CrossRef] [PubMed]

21. Sui, H.; Han, B.G.; Lee, J.K.; Walian, P.; Jap, B.K. Structural basis of water-specific transport through the AQP1 water channel. Nature 2001, 414, 872-878. [CrossRef] [PubMed]

22. Eriksson, U.K.; Fischer, G.; Friemann, R.; Enkavi, G.; Tajkhorshid, E.; Neutze, R. Subangstrom resolution X-ray structure details aquaporin-water interactions. Science 2013, 340, 1346-1349. [CrossRef] [PubMed]

23. Brown, D. The ins and outs of aquaporin-2 trafficking. Am. J. Physiol. Renal Physiol. 2003, 284, F893-F901. [CrossRef] [PubMed]

24. Jung, H.J.; Kwon, T.H. Molecular mechanisms regulating aquaporin-2 in kidney collecting duct. Am. J. Physiol. Renal. Physiol. 2016, 311, F1318-F1328. [CrossRef] [PubMed]

25. Finkelstein, A. Nature of the water permeability increase induced by antidiuretic hormone (ADH) in toad urinary bladder and related tissues. J. Gen. Physiol. 1976, 68, 137-143. [CrossRef] [PubMed]

26. Chevalier, J.; Parisi, M.J. Bourguet, J. The rate-limiting step in hydrosmotic response of frog urinary bladder. Cell. Tissue. Res. 1983, 228, 345-355. [CrossRef] [PubMed]

27. Nielsen, S.; Frøkiaer, J.; Marples, D.; Kwon, T.H.; Agre, P.; Knepper, M.A. Aquaporins in the kidney: from molecules to medicine. Physiol. Rev. 2002, 82, 205-244. [CrossRef] [PubMed]

28. Moeller, H.B.; Fuglsang, C.H.; Fenton, R.A. Renal aquaporins and water balance disorders. Best Pract. Res. Clin. Endocrinol. Metab. 2016, 30, 277-288. [CrossRef] [PubMed]

29. Luu, D.T.; Maurel, C. Aquaporin trafficking in plant cells: an emerging membrane-protein model. Traffic 2013, 14, 629-635. [CrossRef] [PubMed]

30. Nyblom, M.; Tornroth-Horsefield, S. Regulation of eukaryotic aquaporins. In Aquaporins in Health and Disease: New Molecular Targets for Drug Discovery; Soveral, G., Nielsen, S., Casini, A., Eds.; CRC Press: Boca Raton, FL, USA, 2015; pp. 53-76.

31. Chevalier, A.S.; Chaumont, F. Trafficking of plant plasma membrane aquaporins: multiple regulation levels and complex sorting signals. Plant Cell. Physiol. 2015, 56, 819-829. [CrossRef] [PubMed]

32. Tournaire-Roux, C.; Sutka, M.; Javot, H.; Gout, E.; Gerbeau, P.; Luu, D.T.; Bligny, R.; Maurel, C. Cytosolic pH regulates root water transport during anoxic stress through gating of aquaporins. Nature 2003, 425, 393-397. [CrossRef] [PubMed]

33. Törnroth-Horsefield, S.; Wang, Y.; Hedfalk, K.; Johanson, U.; Karlsson, M.; Tajkhorshid, E.; Neutze, R.; Kjellbom, P. Structural mechanism of plant aquaporin gating. Nature 2006, 439, 688-694. [CrossRef] [PubMed]

34. Verdoucq, L.; Grondin, A.; Maurel, C. Structure-function analysis of plant aquaporin AtPIP2;1 gating by divalent cations and protons. Biochem. J. 2008, 415, 409-416. [CrossRef] [PubMed]

35. Preston, G.M.; Jung, J.S.; Guggino, W.B.; Agre, P. The mercury-sensitive residue at cysteine 189 in the CHIP28 water channel. J. Biol. Chem. 1993, 268, 17-20. [PubMed]

36. Németh-Cahalan, K.L.; Kalman, K.; Froger, A.; Hall, J.E. Zinc modulation of water permeability reveals that aquaporin 0 functions as a cooperative tetramer. J. Gen. Physiol. 2007, 130, 457-464. [CrossRef] [PubMed]

37. Reichow, S.L.; Clemens, D.M.; Freites, J.A.; Németh-Cahalan, K.L.; Heyden, M.; Tobias, D.J.; Hall, J.E.; Gonen, T. Allosteric mechanism of water-channel gating by $\mathrm{Ca}^{2+}$-calmodulin. Nat. Struct. Mol. Biol. 2013, 20, 1085-1092. [CrossRef] [PubMed] 
38. Ozu, M.; Dorr, R.A.; Gutiérrez, F.; Politi, M.T.; Toriano, R. Human AQP1 is a constitutively open channel that closes by a membrane-tension mediated mechanism. Biophys. J. 2013, 104, 85-95. [CrossRef] [PubMed]

39. Jozefkowicz, C.; Sigaut, L.; Scochera, F.; Soto, G.; Ayub, N.; Pietrasanta, L.I.; Amodeo, G.; González Flecha, F.L.; Alleva, K. PIP water transport and its $\mathrm{pH}$ dependence are regulated by tetramer stoichiometry. Biophys. J. 2016, 110, 1312-1321. [CrossRef] [PubMed]

40. Smith, A.J.; Jin, B.J.; Ratelade, J.; Verkman, A.S. Aggregation state determines the localization and function of M1- and M23-aquaporin-4 in astrocytes. J. Cell. Biol. 2014, 204, 559-573. [CrossRef] [PubMed]

41. Engel, A.; Fujiyoshi, Y.; Gonen, T.; Walz, T. Junction-forming aquaporins. Curr. Opin. Struct. Biol. 2008, 18, 229-235. [CrossRef] [PubMed]

42. Yaneff, A.; Vitali, V.; Amodeo, G. PIP1 aquaporins: Intrinsic water channels or PIP2 aquaporin modulators? FEBS Lett. 2015, 589, 3508-3515. [CrossRef] [PubMed]

43. Walz, T.; Smith, B.L.; Zeidel, M.L.; Engel, A.; Agre, P. Biologically active two-dimensional crystals of aquaporin CHIP. J. Biol. Chem. 1994, 269, 1583-1586. [PubMed]

44. Zeidel, M.L.; Ambudkar, S.V.; Smith, B.L.; Agre, P. Reconstitution of functional water channels in liposomes containing purified red cell CHIP28 protein. Biochemistry 1992, 31, 7436-7440. [CrossRef] [PubMed]

45. Van-Hoek, A.N.; Verkman, A.S. Functional reconstitution of the isolated erythrocyte water channel CHIP28. J. Biol. Chem. 1992, 267, 18267-18269. [PubMed]

46. Zeidel, M.L.; Nielsen, S.; Smith, B.L.; Ambudkar, S.V.; Maunsbach, A.B.; Agre, P. Ultrastructure, pharmacological inhibition, and transport selectivity of aquaporin channel-forming integral protein in proteoliposomes. Biochemistry 1994, 33, 1606-1615. [CrossRef] [PubMed]

47. Chandy, G.; Zampighi, G.A.; Kreman, M.; Hall, J.E. Comparison of the water transporting properties of MIP and AQP1. J. Membr. Biol. 1997, 159, 29-39. [CrossRef] [PubMed]

48. Denker, B.M.; Smith, B.L.; Kuhajda, F.P.; Agre, P. Identification, purification, and partial characterization of a novel Mr 28,000 integral membrane protein from erythrocytes and renal tubules. J. Biol. Chem. 1988, 263, 15634-15642. [PubMed]

49. Macey, R.I. Transport of water and urea in red blood cells. Am. J. Physiol. 1984, 246, C195-C203. [CrossRef] [PubMed]

50. Marinelli, R.A.; Tietz, P.S.; Caride, A.J.; Huang, B.Q.; LaRusso, N.F. Water transporting properties of hepatocyte basolateral and canalicular plasma membrane domains. J. Biol. Chem. 2003, 278, 43157-43162. [CrossRef] [PubMed]

51. Chara, O.; Ford, P.; Rivarola, V.; Parisi, M.; Capurro, C. Asymmetry in the osmotic response of a rat cortical collecting duct cell line: role of aquaporin-2. J. Membr. Biol. 2005, 207, 143-150. [CrossRef] [PubMed]

52. Alleva, K.; Niemietz, C.M.; Sutka, M.; Maurel, C.; Parisi, M.; Tyerman, S.D.; Amodeo, G. Plasma membrane of Beta vulgaris storage root shows high water channel activity regulated by cytoplasmic $\mathrm{pH}$ and a dual range of calcium concentrations. J. Exp. Bot. 2006, 57, 609-662. [CrossRef] [PubMed]

53. Yaneff, A.; Sigaut, L.; Marquez, M.; Alleva, K.; Pietrasanta, L.I.; Amodeo, G. Heteromerization of PIP aquaporins affects their intrinsic permeability. Proc. Natl. Acad. Sci. USA 2014, 111, 231-236. [CrossRef] [PubMed]

54. Horner, A.; Zocher, F.; Preiner, J.; Ollinger, N.; Siligan, C.; Akimov, S.A.; Pohl, P. The mobility of single-file water molecules is governed by the number of $\mathrm{H}$-bonds they may form with channel-lining residues. Sci. Adv. 2015, 1, e1400083. [CrossRef] [PubMed]

55. Horner, A.; Siligan, C.; Cornean, A.; Pohl, P. Positively charged residues at the channel mouth boost single-file water flow. Faraday Discuss. 2018. [CrossRef] [PubMed]

56. Tani, K.; Mitsuma, T.; Hiroaki, Y.; Kamegawa, A.; Nishikawa, K.; Tanimura, Y.; Fujiyoshi, Y. Mechanism of aquaporin-4's fast and highly selective water conduction and proton exclusion. J. Mol. Biol. 2009, 389, 694-706. [CrossRef] [PubMed]

57. Alberga, D.; Nicolotti, N.; Lattanzi, G.; Nicchia, G.P.; Frigeri, A.; Pisani, F.; Benfenati, V.; Mangiatordi, G.F. A new gating site in human aquaporin-4: Insights from molecular dynamics simulations. Biochim. Biophys. Acta 2014, 1838, 3052-3060. [CrossRef] [PubMed]

58. Kaptan, S.; Assentoft, M.; Schneider, H.P.; Fenton, R.A.; Deitmer, J.D.; MacAulay, N.; de Groot, B.L. H95 is a pH-dependent gate in aquaporin 4. Structure 2015, 23, 2309-2318. [CrossRef] [PubMed]

59. Törnroth-Horsefield, S.; Hedfalk, K.; Fischer, G.; Lindkvist-Petersson, K.; Neutze, R. Structural insights into eukaryotic aquaporin regulation. FEBS Lett. 2010, 584, 2580-2588. [CrossRef] [PubMed] 
60. Hedfalk, K.; Törnroth-Horsefield, S.; Nyblom, M.; Johanson, U.; Kjellbom, P.; Neutze, R. Aquaporin gating. Curr. Opin. Struct. Biol. 2006, 16, 447-456. [CrossRef] [PubMed]

61. Verdoucq, L.; Rodrigues, O.; Martiniè, A.; Luu, D.T.; Maurel, C.; Martinière, A.; Maurel, C. Plant aquaporins on the move: reversible phosphorylation, lateral motion and cycling. Curr. Opin. Plant. Biol. 2014, 22, 101-107. [CrossRef] [PubMed]

62. Frick, A.; Järvå, M.; Törnroth-Horsefield, S. Structural basis for $\mathrm{pH}$ gating of plant aquaporins. FEBS Lett. 2013, 587, 989-993. [CrossRef] [PubMed]

63. Nyblom, S.L.M.; Frick, A.; Wang, Y.; Ekvall, M.; Hallgren, K.; Hedfalk, K.; Neutze, R.; Tajkhorshid, E.; Törnroth-Horsefield, S. Structural and functional analysis of SoPIP2;1 mutants adds insight into plant aquaporin gating. J. Mol. Biol. 2009, 387, 653-668. [CrossRef] [PubMed]

64. Fischer, G.; Kosinska-Eriksson, U.; Aponte-Santamaría, C.; Palmgren, M.; Geijer, C.; Hedfalk, K.; Hohmann, S.; de Groot, B.L.; Neutze, R.; Lindkvist-Petersson, K. Crystal structure of a yeast aquaporin at $1.15 \AA$ Reveals a novel gating mechanism. PLoS Biol. 2009, 7, e1000130. [CrossRef] [PubMed]

65. Németh-Cahalan, K.L.; Kalman, K.; Hall, J.E. Molecular basis of $\mathrm{pH}$ and $\mathrm{Ca}^{2+}$ regulation of aquaporin water permeability. J. Gen. Physiol. 2004, 123, 573-580. [CrossRef] [PubMed]

66. Gonen, T.; Cheng, Y.; Kistler, J.; Walz, T. Aquaporin-0 membrane junctions form upon proteolytic cleavage. J. Mol. Biol. 2004, 342, 1337-1345. [CrossRef] [PubMed]

67. Gonen, T.; Cheng, Y.; Sliz, P.; Hiroaki, Y.; Fujiyoshi, Y.; Harrison, S.C.; Walz, T. Lipid-protein interactions in double-layered two-dimensional AQP0 crystals. Nature 2005, 438, 633-638. [CrossRef] [PubMed]

68. Saboe, P.O.; Rapisarda, C.; Kaptan, S.; Hsiao, Y.S.; Summers, S.R.; De Zorzi, R.; Dukovski, D.; Yu, J.; de Groot, B.L.; Kumar, M.; et al. Role of pore-lining residues in defining the rate of water conduction by aquaporin-0. Biophys. J. 2017, 112, 953-965. [CrossRef] [PubMed]

69. Fields, J.B.; Németh-Cahalan, K.L.; Freites, J.A.; Vorontsova, I.; Hall, J.E.; Tobias, D.J. Calmodulin gates Aquaporin 0 permeability through a positively charged cytoplasmic loop. J. Biol. Chem. 2017, 292, 185-195. [CrossRef] [PubMed]

70. Wang, Y.; Schulten, K.; Tajkhorshid, E. What makes an aquaporin a glycerol channel? A comparative study of AqpZ and GlpF. Structure 2005, 13, 1107-1118. [CrossRef] [PubMed]

71. Jiang, J.; Daniels, B.V; Fu, D. Crystal structure of AqpZ tetramer reveals two distinct Arg-189 conformations associated with water permeation through the narrowest constriction of the water-conducting channel. J. Biol. Chem. 2006, 281, 454-460. [CrossRef] [PubMed]

72. Lindahl, V.; Gourdon, P.; Andersson, M.; Hess, B. Permeability and ammonia selectivity in aquaporin TIP2;1: linking structure to function. Sci. Rep. 2018, 8, 2995. [CrossRef] [PubMed]

73. Leitaõ, L.; Prista, C.; Moura, T.F.; Loureiro-Dias, M.C.; Soveral, G. Grapevine Aquaporins: Gating of a tonoplast intrinsic protein (TIP2;1) by cytosolic pH. PLoS ONE 2012, 7, e33219. [CrossRef] [PubMed]

74. Conner, A.C.; Brown, J.E.; Bill, R.M. Membrane trafficking of aquaporin 1 is mediated by protein kinase C via microtubules and regulated by tonicity. Biochemistry 2010, 49, 821-823. [CrossRef] [PubMed]

75. Noda, Y.; Sasaki, S. Trafficking mechanism of water channel aquaporin-2. Biol. Cell. 2005, 97, 885-892. [CrossRef] [PubMed]

76. Kosugi-Tanaka, C.; Li, X.; Yao, C.; Akamatsu, T.; Kanamori, N.; Hosoi, K. Protein kinase A-regulated membrane trafficking of a green fluorescent protein-aquaporin 5 chimera in MDCK cells. Biochim. Biophys. Acta 2006, 1763, 337-344. [CrossRef] [PubMed]

77. Garcia, F.; Kierbel, A.; Larocca, M.C.; Gradilone, S.A.; Splinter, P.; Larusso, N.F.; Marinelli, R.A. The water channel aquaporin-8 is mainly intracellular in rat hepatocytes, and its plasma membrane insertion is stimulated by cyclic AMP. J. Biol. Chem. 2001, 276, 12147-12152. [CrossRef] [PubMed]

78. Zelenina, M.; Zelenin, S.; Bondar, A.A.; Brismar, H.; Aperia, A. Water permeability of aquaporin-4 is decreased by protein kinase C and dopamine. Am. J. Physiol. Renal. Physiol. 2002, 283, F309-F3182. [CrossRef] [PubMed]

79. Yaneff, A.; Sigaut, L.; Gómez, N.; Aliaga Fandiño, C.; Alleva, K.; Pietrasanta, L.I.; Amodeo, G. Loop B serine of a plasma membrane aquaporin type PIP2 but not PIP1 plays a key role in pH sensing. Biochim. Biophys. Acta 2016, 1858, 2778-2787. [CrossRef] [PubMed]

80. De Groot, B.L.; Frigato, T.; Helms, V.; Grubmüller, H. The mechanism of proton exclusion in the aquaporin-1 water channel. J. Mol. Biol. 2003, 333, 279-293. [CrossRef] [PubMed] 
81. Wu, B.; Steinbronn, C.; Alsterfjord, M.; Zeuthen, T.; Beitz, E. Concerted action of two cation filters in the aquaporin water channel. EMBO J. 2009, 28, 2188-2194. [CrossRef] [PubMed]

82. Wree, D.; Wu, B.; Zeuthen, T.; Beitz, E. Requirement for asparagine in the aquaporin NPA sequence signature motifs for cation exclusion. FEBS J. 2011, 278, 740-748. [CrossRef] [PubMed]

83. Rothert, M.; Rönfeldt, D.; Beitz, E. Electrostatic attraction of weak monoacid anions increases probability for protonation and passage through aquaporins. J. Biol. Chem. 2017, 292, 9358-9364. [CrossRef] [PubMed]

84. Oliva, R.; Calamita, G.; Thornton, J.M.; Pellegrini-Calace, M. Electrostatics of aquaporin and aquaglyceroporin channels correlates with their transport selectivity. Proc. Natl. Acad. Sci. USA 2010, 107, 4135-4140. [CrossRef] [PubMed]

85. Jensen, M.Ø.; Röthlisberger, U.; Rovira, C. Hydroxide and proton migration in aquaporins. Biophys. J. 2005, 89, 1744-1759. [CrossRef] [PubMed]

86. Rambow, J.; Wu, B.; Rönfeldt, D.; Beitz, E. Aquaporins with anion/monocarboxylate permeability: mechanisms, relevance for pathogen-host interactions. Front. Pharmacol. 2014, 5, 199. [CrossRef] [PubMed]

87. Agre, P.; Lee, M.D.; Devidas, S.; Guggino, W.B. Aquaporins and ion conductance. Science 1997, 275, 1490-1492. [CrossRef] [PubMed]

88. Campbell, E.M.; Birdsell, D.N.; Yool, A.J. The activity of human aquaporin 1 as a cGMP-gated cation channel is regulated by tyrosine phosphorylation in the carboxyl-terminal domain. Mol. Pharmacol. 2012, 81, 97-105. [CrossRef] [PubMed]

89. Anthony, T.L.; Brooks, H.L.; Boassa, D.; Leonov, S.; Yanochko, G.M.; Regan, J.W.; Yool, A.J. Cloned human aquaporin-1 is a cyclic GMP-gated ion channel. Mol. Pharmacol. 2000, 57, 576-588. [CrossRef] [PubMed]

90. Boassa, D.; Yool, A.J. Single amino acids in the carboxyl terminal domain of aquaporin-1 contribute to cGMP-dependent ion channel activation. BMC Physiol. 2003, 3, 12. [CrossRef] [PubMed]

91. Yu, J.; Yool, A.J.; Schulten, K.; Tajkhorshid, E. Mechanism of gating and ion conductivity of a possible tetrameric pore in aquaporin-1. Structure 2006, 14, 1411-1423. [CrossRef] [PubMed]

92. Kourghi, M.; De Ieso, M.L.; Nourmohammadi, S.; Pei, J.V.; Yool, A.J. Identification of loop D domain amino acids in the human Aquaporin-1 channel involved in activation of the ionic conductance and inhibition by AqB011. Front. Chem. 2018, 6, 142. [CrossRef] [PubMed]

93. Yanochko, G.M.; Yool, A.J. Regulated cationic channel function in Xenopus oocytes expressing Drosophila big brain. J. Neurosci. 2002, 22, 2530-2540. [CrossRef] [PubMed]

94. Yanochko, G.M.; Yool, A.J. Block by extracellular divalent cations of Drosophila big brain channels expressed in Xenopus oocytes. Biophys. J. 2004, 86, 1470-1478. [CrossRef]

95. Yool, A.J.; Brokl, O.H.; Pannabecker, T.L.; Dantzler, W.H.; Stamer, W.D. Tetraethylammonium block of water flux in Aquaporin-1 channels expressed in kidney thin limbs of Henle's loop and a kidney-derived cell line. BMC Physiol. 2002, 2, 4. [CrossRef]

96. Saparov, S.M.; Kozono, D.; Rothe, U.; Agre, P.; Pohl, P. Water and ion permeation of aquaporin-1 in planar lipid bilayers. Major differences in structural determinants and stoichiometry. J. Biol. Chem. 2001, 276, 31515-31520. [CrossRef] [PubMed]

97. Fu, D.; Libson, A.; Miercke, L.J.; Weitzman, C.; Nollert, P.; Krucinski, J.; Stroud, R.M. Structure of a glycerol-conducting channel and the basis for its selectivity. Science 2000, 290, 481-486. [CrossRef] [PubMed]

98. Yool, A.J.; Weinstein, A.M. New roles for old holes: ion channel function in aquaporin-1. News Physiol. Sci. 2002, 17, 68-72. [CrossRef] [PubMed]

99. Kourghi, M.; Pei, J.V.; De Ieso, M.L.; Flynn, G.; Yool, A.J. Bumetanide derivatives AqB007 and AqB011 selectively block the Aquaporin-1 ion channel conductance and slow cancer cell migration. Mol. Pharmacol. 2016, 89, 133-140. [CrossRef] [PubMed]

100. Yasui, M.; Hazama, A.; Kwon, T.H.; Nielsen, S.; Guggino, W.B; Agre, P. Rapid gating and anion permeability of an intracellular aquaporin. Nature 1999, 402, 184-187. [CrossRef] [PubMed]

101. Ikeda, M.; Beitz, E.; Kozono, D.; Guggino, W.B.; Agre, P.; Yasui, M. Characterization of aquaporin-6 as a nitrate channel in mammalian cells. Requirement of pore-lining residue threonine 63. J. Biol. Chem. 2002, 277, 39873-39879. [CrossRef] [PubMed]

102. Hazama, A.; Kozono, D.; Guggino, W.B.; Agre, P.; Yasui, M. Ion permeation of AQP6 water channel protein. Single channel recordings after $\mathrm{Hg}^{2+}$ activation. J. Biol. Chem. 2002, 277, 29224-29230. [CrossRef] [PubMed] 
103. Liu, K.; Kozono, D.; Kato, Y.; Agre, P.; Hazama, A.; Yasui, M. Conversion of aquaporin 6 from an anion channel to a water-selective channel by a single amino acid substitution. Proc. Natl. Acad. Sci. USA 2005, 102, 2192-2197. [CrossRef] [PubMed]

104. Qin, X.; Boron, W.F. Mutation of a single amino acid converts the human water channel aquaporin 5 into an anion channel. Am. J. Physiol. Cell. Physiol. 2013, 305, C663-C672. [CrossRef] [PubMed]

105. Weaver, C.D.; Shomer, N.H.; Louis, C.F.; Roberts, D.M. Nodulin 26, a nodule-specific symbiosome membrane protein from soybean, is an ion channel. J. Biol. Chem. 1994, 269, 17858-17862. [PubMed]

106. Rivers, R.L.; Dean, R.M.; Chandy, G.; Hall, J.E.; Roberts, D.M.; Zeidel, M.L. Functional analysis of nodulin 26, an aquaporin in soybean root nodule symbiosomes. J. Biol. Chem. 1997, 272, 16256-16261. [CrossRef] [PubMed]

107. Byrt, C.S.; Zhao, M.; Kourghi, M.; Bose, J.; Henderson, S.W.; Qiu, J.; Gilliham, M.; Schultz, C.; Schwarz, M.; Ramesh, S.A.; et al. Non-selective cation channel activity of aquaporin AtPIP2;1 regulated by $\mathrm{Ca}^{2+}$ and $\mathrm{pH}$. Plant. Cell. Environ. 2017, 40, 802-815. [CrossRef] [PubMed]

108. Kourghi, M.; Nourmohammadi, S.; Pei, J.V.; Qiu, J.; McGaughey, S.; Tyerman, S.D.; Byrt, C.S.; Yool, A.J. Divalent cations regulate the ion conductance properties of diverse classes of Aquaporins. Int. J. Mol. Sci. 2017, 18, 2323. [CrossRef] [PubMed]

109. Shelden, M.C.; Howitt, S.M.; Kaiser, B.N.; Tyerman, S.D. Identification and functional characterization of aquaporins in the grapevine Vitis vinifera. Funct. Plant Biol. 2009, 36, 1065-1078. [CrossRef]

110. Wang, C.; Hu, H.; Qin, X.; Zeise, B.; Xu, D.; Rappel, W.J.; Boron, W.F.; Schroeder, J.I. Reconstitution of $\mathrm{CO}_{2}$ regulation of SLAC1 anion channel and function of $\mathrm{CO}_{2}$-permeable PIP2;1 Aquaporin as carbonic anhydrase-4 Interactor. Plant Cell 2016, 28, 568-582. [CrossRef] [PubMed]

111. Yool, A.J.; Campbell, E.M. Structure, function and translational relevance of aquaporin dual water and ion channels. Mol. Aspects. Med. 2012, 33, 553-561. [CrossRef] [PubMed]

112. Kitchen, P.; Day, R.E.; Salman, M.M.; Conner, M.T.; Bill, R.M.; Conner, A.C.; Nakhoul, N.L.; Davis, B.A.; Romero, M.F.; Boron, W.F. Beyond water homeostasis: Diverse functional roles of mammalian aquaporins. Biochim. Biophys. Acta 2015, 1850, 2410-2421. [CrossRef] [PubMed]

113. Nakhoul, N.L.; Davis, B.A.; Romero, M.F.; Boron, W.F. Effect of expressing the water channel aquaporin-1 on the $\mathrm{CO}_{2}$ permeability of Xenopus oocytes. Am. J. Phys. 1998, 274, C543-C548. [CrossRef]

114. Herrera, M.; Hong, N.J.; Garvin, J.L. Aquaporin-1 transports NO across cell membranes. Hypertension 2006, 48, 157-164. [CrossRef] [PubMed]

115. Geyer, R.R.; Musa-Aziz, R.; Qin, X.; Boron, W.F. Relative $\mathrm{CO}_{2} / \mathrm{NH}_{3}$ selectivities of mammalian aquaporins 0-9. Am. J. Physiol. Cell. Physiol. 2013, 304, 985-994. [CrossRef] [PubMed]

116. Missner, A.; Pohl, P. 110 years of the Meyer-Overton rule: Predicting membrane permeability of gases and other small compounds. ChemPhysChem 2009, 10, 1405-1414. [CrossRef] [PubMed]

117. Saparov, S.M.; Antonenko, Y.N.; Pohl, P.A. New model of weak acid permeation through membranes revisited: Does overton still rule? Biophys. J. 2006, 90, L86-L88. [CrossRef] [PubMed]

118. Endeward, V.; Cartron, J.P.; Ripoche, P.; Gros, G. Red cell membrane $\mathrm{CO}_{2}$ permeability in normal human blood and in blood deficient in various blood groups, and effect of DIDS. Transfus. Clin. Biol. 2006, 13, 123-127. [CrossRef] [PubMed]

119. Wang, Y.; Cohen, J.; Boron, W.F.; Schulten, K.; Tajkhorshid, E. Exploring gas permeability of cellular membranes and membrane channels with molecular dynamics. J. Struct. Biol. 2007, 157, 534-544. [CrossRef] [PubMed]

120. Hub, J.S.; de Groot, B.L. Does $\mathrm{CO}_{2}$ permeate through aquaporin-1? Biophys. J. 2006, 91, 842-848. [CrossRef] [PubMed]

121. Alexandre, J.; Lassalles, J.P. Hydrostatic and osmotic pressure activated channel in plant vacuole. Biophys. J. 1991, 60, 1326-1336. [CrossRef]

122. Niemietz, C.M.; Tyerman, S.D. Characterization of water channels in wheat root membrane vesicles. Plant Physiol. 1997, 115, 561-567. [CrossRef] [PubMed]

123. Meinild, A.K.; Klaerke, D.A.; Zeuthen, T. Bidirectional water fluxes and specificity for small hydrophilic molecules in aquaporins 0-5. J. Biol. Chem. 1998, 273, 32446-32451. [CrossRef] [PubMed]

124. Ohshima, Y.; Iwasaki, I.; Suga, S.; Murakami, M.; Inoue, K.; Maeshima, M. Low aquaporin content and low osmotic water permeability of the plasma and vacuolar membranes of a CAM plant Graptopetalum paraguayense: comparison with radish. Plant Cell. Physiol. 2001, 42, 1119-1129. [CrossRef] [PubMed] 
125. Vandeleur, R.; Niemietz, C.; Tilbrook, J.; Tyerman, S.D. Roles of aquaporins in root responses to irrigation. Plant Soil 2005, 274, 141-161. [CrossRef]

126. Ozu, M.; Dorr, R.A.; Politi, T.; Parisi, M.; Toriano, R. Water flux through human aquaporin 1: Inhibition by intracellular furosemide and maximal response with high osmotic gradients. Eur. Biophys. J. 2011, 40, 737-746. [CrossRef] [PubMed]

127. Hill, A.E.; Shachar-Hill, B.; Shachar-Hill, Y. What are aquaporins for? J. Membr. Biol. 2004, 197, 1-32. [CrossRef] [PubMed]

128. Soveral, G.; Macey, R.I.; Moura, T.F. Water permeability of brush border membrane vesicles from kidney proximal tubule. J. Membr. Biol. 1997, 158, 219-228. [CrossRef] [PubMed]

129. Wan, X.; Steudle, E.; Hartung, W. Gating of water channels (aquaporins) in cortical cells of young corn roots by mechanical stimuli (pressure pulses): Effects of $\mathrm{ABA}$ and of $\mathrm{HgCl}_{2}$. J. Exp. Bot. 2004, 55, 411-422. [CrossRef] [PubMed]

130. Ye, Q.; Wiera, B.; Steudle, E. A cohesion/tension mechanism explains the gating of water channels (aquaporins) in Chara internodes by high concentration. J. Exp. Bot. 2004, 55, 449-461. [CrossRef] [PubMed]

131. Soveral, G.; Madeira, A.; Loureiro-Dias, M.C.; Moura, T.F. Membrane tension regulates water transport in yeast. Biochim. Biophys. Acta 2008, 1778, 2573-2579. [CrossRef] [PubMed]

132. Leitão, L.; Prista, C.; Loureiro-Dias, M.C.; Moura, T.F.; Soveral, G. The grapevine tonoplast aquaporin TIP2;1 is a pressure gated water channel. Biochem. Biophys. Res. Commun. 2014, 450, 289-294. [CrossRef] [PubMed]

133. Hill, A.E.; Shachar-Hill, Y. Are Aquaporins the missing transmembrane Osmosensors? J. Membr. Biol. 2015, 248, 753-765. [CrossRef] [PubMed]

134. Tong, J.; Briggs, M.M.; McIntosh, T.J. Water permeability of Aquaporin-4 channel depends on bilayer composition, thickness, and elasticity. Biophys. J. 2012, 103, 1899-1908. [CrossRef] [PubMed]

135. Goldman, R.P.; Jozefkowicz, C.; Canessa Fortuna, A.; Sutka, M.; Alleva, K.; Ozu, M. Tonoplast (BvTIP1;2) and plasma membrane (BvPIP2;1) aquaporins show different mechanosensitive properties. FEBS Lett. 2017, 591, 1555-1565. [CrossRef] [PubMed]

136. Sukharev, S.; Sachs, F. Molecular force transduction by ion channels-Diversity and unifying principles. J. Cell Sci. 2012, 125, 3075-3083. [CrossRef] [PubMed]

137. Anishkin, A.; Loukin, S.H.; Teng, J.; Kung, C. Feeling the hidden mechanical forces in lipid bilayer is an original sense. Proc. Natl. Acad. Sci. USA 2014, 111, 7898-7905. [CrossRef] [PubMed]

138. Martinac, B.; Bavi, N.; Ridone, P.; Nikolaev, Y.A.; Martinac, A.D.; Nakayama, Y.; Rohde, P.R.; Bavi, O. Tuning ion channel mechanosensitivity by asymmetry of the transbilayer pressure profile. Biophys. Rev. 2018. [CrossRef] [PubMed]

139. Cox, C.D.; Bavi, N.; Martinac, B. Bacterial mechanosensors. Annu. Rev. Physiol. 2018, 80, 71-93. [CrossRef] [PubMed]

140. Tong, J.; Wu, Z.; Briggs, M.M.; Schulten, S.; Mc Intosh, T.J. The water permeability and pore entrance structure of Aquaporin-4 depend on lipid bilayer thickness. Biophys. J. 2016, 111, 90-99. [CrossRef] [PubMed]

141. Gravelle, S.; Joly, L.; Detcheverry, F.; Ybert, C.; Cottin-Bizonne, C.; Bocquet, L. Optimizing water permeability through the hourglass shape of aquaporins. Proc. Natl. Acad. Sci. USA 2013, 110, 16367-16372. [CrossRef] [PubMed]

142. Russ, W.P.; Engelman, D.M. The GxxxG motif: A framework for transmembrane helix-helix association. J. Mol. Biol. 2000, 296, 911-919. [CrossRef] [PubMed]

143. Balleza, D. Toward understanding protocell mechanosensation. Origins Life Evol. Biosphere 2011, 41, $281-304$. [CrossRef] [PubMed]

144. Möller, C.; Fotiadis, D.; Suda, K.; Engel, A.; Kessler, M.; Müller, D.J. Determining molecular forces that stabilize human aquaporin-1. J. Struct. Biol. 2003, 142, 369-378. [CrossRef]

145. Kitchen, P.; Conner, M.T.; Bill, R.M.; Conner, A.C. Structural determinants of oligomerization of the aquaporin-4 channel. J. Biol. Chem. 2016, 291, 6858-6871. [CrossRef] [PubMed]

146. Pohl, P.; Saparov, S.M.; Borgnia, M.J.; Agre, P. Highly selective water channel activity measured by voltage clamp: Analysis of planar lipid bilayers reconstituted with purified AqpZ. Proc. Natl. Acad. Sci. USA 2001, 98, 9624-9629. [CrossRef] [PubMed]

147. Preiner, J.; Horner, A.; Karner, A.; Ollinger, N.; Siligan, S.; Pohl, P.; Hinterdorfer, P. High-speed AFM images of thermal motion provide stiffness map of interfacial membrane protein moieties. Nano Lett. 2015, 15, 759-763. [CrossRef] [PubMed] 
148. Bienert, G.P.; Cavez, D.; Besserer, A.; Berny, M.C.; Gilis, D.; Rooman, M.; Chaumont, F. A conserved cysteine residue is involved in disulfide bond formation between plant plasma membrane aquaporin monomers. Biochem. J. 2012, 445, 101-111. [CrossRef] [PubMed]

149. Fetter, K.; Van Wilder, V.; Moshelion, M.; Chaumont, F. Interactions between plasma membrane Aquaporins modulate their water channel activity. Plant Cell 2004, 16, 215-228. [CrossRef] [PubMed]

150. Zelazny, E.; Borst, J.W.; Muylaert, M.; Batoko, H.; Hemminga, M.A.; Chaumont, F. FRET imaging in living maize cells reveals that plasma membrane aquaporins interact to regulate their subcellular localization. Proc. Natl. Acad. Sci. USA 2007, 104, 12359-12364. [CrossRef] [PubMed]

151. Berny, M.C.; Gilis, D.; Rooman, M.; Chaumont, F. Single mutations in the transmembrane domains of maize plasma membrane Aquaporins affect the activity of monomers within a Heterotetramer. Mol. Plant 2016, 9, 986-1003. [CrossRef] [PubMed]

152. Vajpai, M.; Mukherjee, M.; Sankararamakrishnan, R. Cooperativity in plant plasma membrane intrinsic proteins (PIPs): Mechanism of increased water transport in maize PIP1 channels in hetero-tetramers. Sci. Rep. 2018, 8, 12055. [CrossRef] [PubMed]

153. Lundbaek, J.A.; Birn, P.; Tape, S.E.; Toombes, G.E.; Søgaard, R.; Koeppe, R.E., II; Gruner, S.M.; Hansen, A.J.; Andersen, O.S. Capsaicin regulates voltage-dependent sodium channels by altering lipid bilayer elasticity. Mol. Pharmacol. 2005, 68, 680-689. [CrossRef] [PubMed]

154. Aponte-Santamaría, C.; Briones, R.; Schenk, A.D.; Walz, T.; de Groot, B.L. Molecular driving forces defining lipid positions around aquaporin-0. Proc. Natl. Acad. Sci. USA 2012, 109, 9887-9892. [CrossRef] [PubMed]

155. Stansfeld, P.J; Jefferys, E.E.; Sansom, M.S.P. Multiscale simulations reveal conserved patterns of lipid interactions with Aquaporins. Structure 2013, 21, 810-819. [CrossRef] [PubMed]

156. Roche, J.V.; Törnroth-Horsefield, S. Aquaporin protein-protein interactions. Int. J. Mol. Sci. 2017, $18,2255$. [CrossRef] [PubMed]

157. Hiroaki, Y.; Tani, K.; Kamegawa, A.; Gyobu, N.; Nishikawa, K.; Suzuki, H.; Walz, T.; Sasaki, S.; Mitsuoka, K.; Kimura, K.; et al. Implications of the aquaporin-4 structure on array formation and cell adhesion. J. Mol. Biol. 2006, 355, 628-639. [CrossRef] [PubMed]

158. Costello, M.J.; McIntosh, T.J.; Robertson, J.D. Distribution of gap junctions and square array junctions in the mammalian lens. Invest. Ophthalmol. Vis. Sci. 1989, 30, 975-989. [PubMed]

159. Rash, J.E.; Yasumura, T.; Hudson, C.S.; Agre, P.; Nielsen, S. Direct immunogold labeling of aquaporin-4 in square arrays of astrocyte and ependymocyte plasma membranes in rat brain and spinal cord. Proc. Natl. Acad. Sci. USA 1998, 95, 11981-11986. [CrossRef] [PubMed]

160. Zampighi, G.; Simon, S.A.; Robertson, J.D.; McIntosh, T.J.; Costello, M.J. On the structural organization of isolated bovine lens fiber junctions. J. Cell. Biol. 1982, 93, 175-189. [CrossRef] [PubMed]

161. Takemoto, L.; Takehana, M.; Horwitz, J. Covalent changes in MIP26K during aging of the human lens membrane. Invest. Ophthalmol. Vis. Sci. 1986, 27, 443-446. [PubMed]

162. Lu, M.; Lee, M.D.; Smith, B.L.; Jung, J.S.; Agre, P.; Verdijk, M.A.; Merkx, G.; Rijss, J.P.; Deen, P.M. The human AQP4 gene: definition of the locus encoding two water channel polypeptides in brain. Proc. Natl. Acad. Sci. USA 1996, 93, 10908-10912. [CrossRef] [PubMed]

163. Kistler, J.; Bullivant, S. Lens gap junctions and orthogonal arrays are unrelated. FEBS Lett. 1980, 111, 73-78. [CrossRef]

164. Furman, C.S.; Gorelick-Feldman, D.A.; Davidson, K.G.; Yasumura, T.; Neely, J.D.; Agre, P.; Rash, J.E. Aquaporin-4 square array assembly: Opposing actions of M1 and M23 isoforms. Proc. Natl. Acad. Sci. USA 2003, 100, 13609-13614. [CrossRef] [PubMed]

165. Ball, L.E.; Little, M.; Nowak, M.W.; Garland, D.L.; Crouch, R.K.; Schey, K.L. Water permeability of C-terminally truncated aquaporin 0 (AQP0 1-243) observed in the aging human lens. Invest. Ophthalmol. Vis. Sci. 2003, 44, 4820-4828. [CrossRef] [PubMed]

166. Kumari, S.S.; Gandhi, J.; Mustehsan, M.H.; Eren, S.; Varadaraj, K. Functional characterization of an AQP0 missense mutation, R33C, that causes dominant congenital lens cataract, reveals impaired cell-to-cell adhesion. Exp. Eye. Res. 2013, 116, 371-385. [CrossRef] [PubMed]

167. Gu, F.; Zhai, H.; Li, D.; Zhao, L.; Li, C.; Huang, S.; Ma, X. A novel mutation in major intrinsic protein of the lens gene (MIP) underlies autosomal dominant cataract in a chinese family. Mol. Vis. 2007, 13, 1651-1656. [PubMed] 
168. Jensen, M.Ø.; Dror, R.O.; Xu, H.; Borhani, D.W.; Arkin, I.T.; Eastwood, M.P.; Shaw, D.E. Dynamic control of slow water transport by aquaporin 0 : implications for hydration and junction stability in the eye lens. Proc. Natl. Acad. Sci. USA 2008, 2008 105, 14430-14435. [CrossRef]

169. Harries, W.E.C.; Akhavan, D.; Miercke, L.J.W.; Khademi, S.; Stroud, R.M. The channel architecture of aquaporin 0 at a 2.2-Å resolution. Proc. Natl. Acad. Sci. USA 2004, 101, 14045-14050. [CrossRef] [PubMed]

170. Ho, J.D.; Yeh, R.; Sandstrom, A.; Chorny, I.; Harries, W.E.; Robbins, R.A.; Miercke, L.J.; Stroud, R.M. Crystal structure of human aquaporin 4 at $1.8 \AA$ and its mechanism of conductance. Proc. Natl. Acad. Sci. USA 2009, 106, 7437-7442. [CrossRef] [PubMed]

171. Qiu, H.; Ma, S.; Shen, R.; Guo, W. Dynamic and energetic mechanisms for the distinct permeation rate in AQP1 and AQP0. Biochim. Biophys. Acta 2010, 1798, 318-326. [CrossRef] [PubMed]

172. Calvanese, L.; Pellegrini-Calace, M.; Oliva, R. Mutations at key pore-lining positions differentiate the water permeability of fish lens aquaporin from other vertebrates. FEBS Lett. 2010, 584, 4797-4801. [CrossRef] [PubMed]

173. Rash, J.E.; Davidson, K.G.; Yasumura, T.; Furman, C.S. Freeze-fracture and immunogold analysis ofaquaporin-4 (AQP4) square arrays, with models of AQP4 lattice assembly. Neuroscience 2004, 129, 915-934. [CrossRef] [PubMed]

174. Nielsen, S.; Nagelhus, E.A.; Amiry-Moghaddam, M.; Bourque, C.; Agre, P.; Ottersen, O.P. Specialized membrane domains for water transport in glial cells: High-resolution immunogold cytochemistry of aquaporin-4 in rat brain. J. Neurosci. 1997, 17, 171-180. [CrossRef] [PubMed]

175. Zhang, H.; Verkman, A.S. Evidence against involvement of aquaporin-4 in cell-cell adhesion. J. Mol. Biol. 2008, 382, 1136-1143. [CrossRef] [PubMed]

176. Kukulski, W.; Schenk, A.D.; Johanson, U.; Braun, T.; de Groot, B.L.; Fotiadis, D.; Kjellbom, P.; Engel, A. The 5 Å structure of heterologously expressed plant aquaporin SoPIP2;1. J. Mol. Biol. 2005, 350, 611-616. [CrossRef] [PubMed]

177. Laloux, T.; Junqueira, B.; Maistriaux, L.C.; Ahmed, J.; Jurkiewicz, A.; Chaumont, F. Plant and mammal Aquaporins: Same but different. Int. J. Mol. Sci. 2018, 19, 521. [CrossRef] [PubMed]

178. Soto, G.; Alleva, K.; Amodeo, G.; Muschietti, J.; Ayub, N.D. New insight into the evolution of aquaporins from flowering plants and vertebrates: Orthologous identification and functional transfer is possible. Gene 2012, 503, 165-176. [CrossRef] [PubMed]

179. Di Giorgio, J.P.; Soto, G.; Alleva, K.; Jozefkowicz, C.; Amodeo, G.; Muschietti, J.P.; Ayub, N.D. Prediction of aquaporin function by integrating evolutionary and functional analyses. J. Membr. Biol. 2014, 247, 107-125. [CrossRef] [PubMed]

(C) 2018 by the authors. Licensee MDPI, Basel, Switzerland. This article is an open access article distributed under the terms and conditions of the Creative Commons Attribution (CC BY) license (http://creativecommons.org/licenses/by/4.0/). 